\title{
Glia-related mechanisms in the anteroventral cochlear nucleus of the adult rat in response to unilateral conductive hearing loss
}

\author{
Verónica Fuentes-Santamaría *, Juan C. Alvarado, Diego F. López-Muñoz, Pedro Melgar-Rojas, \\ María C. Gabaldón-UII and José M. Juiz
}

Facultad de Medicina, Instituto de Investigación en Discapacidades, Neurológicas (IDINE), Universidad de Castilla-La Mancha, Albacete, Spain

Edited by:

Monica Muñoz-Lopez, University of

Castilla-La Mancha, Spain

Reviewed by:

Alino Martinez-Marcos, Universidad

de Castilla-La Mancha, Spain

Ricardo Gómez-Nieto, Universidad

de Salamanca, Spain

\section{*Correspondence:}

Verónica Fuentes-Santamaría,

Facultad de Medicina, Universidad de Castilla-La Mancha, Campus de

Albacete, Calle Almansa, 14, 02006

Albacete, Spain

e-mail:veronica.fuentes@uclm.es
Conductive hearing loss causes a progressive decline in cochlear activity that may result in functional and structural modifications in auditory neurons. However, whether these activity-dependent changes are accompanied by a glial response involving microglia, astrocytes, or both has not yet been fully elucidated. Accordingly, the present study was designed to determine the involvement of glial related mechanisms in the anteroventral cochlear nucleus (AVCN) of adult rats at 1, 4, 7, and $15 \mathrm{~d}$ after removing middle ear ossicles. Quantitative immunohistochemistry analyses at light microscopy with specific markers of microglia or astroglia along with immunocytochemistry at the electron microscopy level were used. Also, in order to test whether trophic support by neurotrophins is modulated in glial cells by auditory activity, the expression and distribution of neurotrophin-3 (NT-3) and its colocalization with microglial or astroglial markers was investigated. Diminished cochlear activity after middle ear ossicle removal leads to a significant ipsilateral increase in the mean gray levels and stained area of microglial cells but not astrocytes in the AVCN at 1 and $4 \mathrm{~d}$ post-lesion as compared to the contralateral side and control animals. These results suggest that microglial cells but not astrocytes may act as dynamic modulators of synaptic transmission in the cochlear nucleus immediately following unilateral hearing loss. On the other hand, NT-3 immunostaining was localized mainly in neuronal cell bodies and axons and was upregulated at 1, 4 and $7 \mathrm{~d}$ post-lesion. Very few glial cells expressed this neurotrophin in both control and experimental rats, suggesting that NT-3 is primarily activated in neurons and not as much in glia after limiting auditory activity in the AVCN by conductive hearing loss.

Keywords: ossicle removal, microglial cells, astrocyte, cochlear nucleus, auditory pathways

\section{INTRODUCTION}

Conductive hearing loss is a condition that results in diminished cochlear nerve synaptic activity due to an inefficient sound transmission from the middle to the inner ear (Conlee and Parks, 1981; Tucci and Rubel, 1985). Physiological studies in adult patients and children who suffer from unilateral conductive ear disease have demonstrated that this hearing impairment results in functional anomalies in brainstem auditory evoked responses (ABRs) (Fria and Sabo, 1980; Ferguson et al., 1998). In both adult and juvenile populations, $A B R$ recordings showed significant delays in wave $\mathrm{V}$ and in the III-IV interwave intervals. This observation has led to the suggestion that conductive hearing loss is associated with alterations at the central level that might have a significant impact on auditory processing. In an attempt to improve the diagnosis and treatment of these patients, animal models of conductive hearing loss have been developed to elucidate the morphological and functional anomalies associated with these pathological responses. In this regard, a series of studies have demonstrated that unilateral restriction of peripheral inputs to central auditory nuclei leads to decreased activity in auditory neurons of the affected side (Tucci et al., 1999, 2001, 2002; Hutson et al., 2007), strengthening of the ipsilateral projection from the cochlear nucleus to inferior colliculus (Moore et al., 1989), alterations in neurotransmitters release and uptake (Potashner et al., 1997; Suneja et al., 1998), redistribution of AMPA and glycine receptor subunits (Whiting et al., 2009), and modifications in the synthesis and composition of glutamate and glycine receptors (Wang et al., 2011).

Imbalance of neurotransmission after bilateral deprivation of cochlear activity results in long-term interactions between microglial cells and deafferented cochlear nucleus neurons (Campos Torres et al., 1999; Fuentes-Santamaria et al., 2012). In response to modifications in chemical and electrical signals from damaged neurons, microglia rapidly changes to an active phenotype promoting the synthesis and release of cellular mediators, as an attempt to restore synaptic homeostasis and function (Bruce-Keller, 1999; Cullheim and Thams, 2007; Hanisch and Kettenmann, 2007). Growth factors, including neurotrophins, and cytokines are activity-dependent signaling molecules involved in the regulation of synaptic activity in 
Table 1 | Antibodies used for Immunohistochemistry.

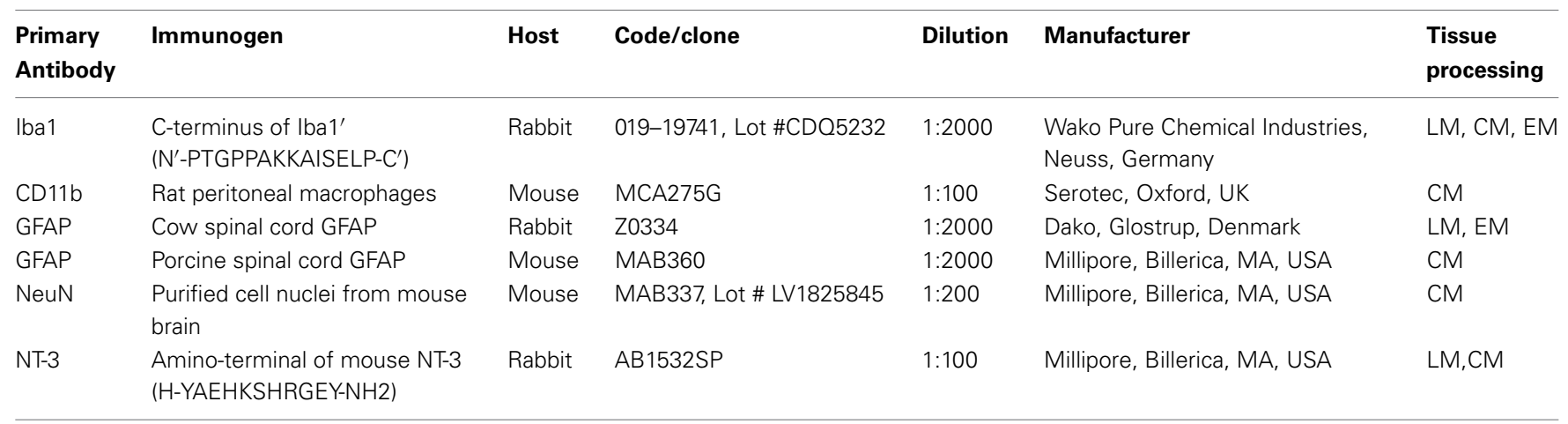

LM, light microscopy; CM, confocal microscopy; EM, electron microscopy.

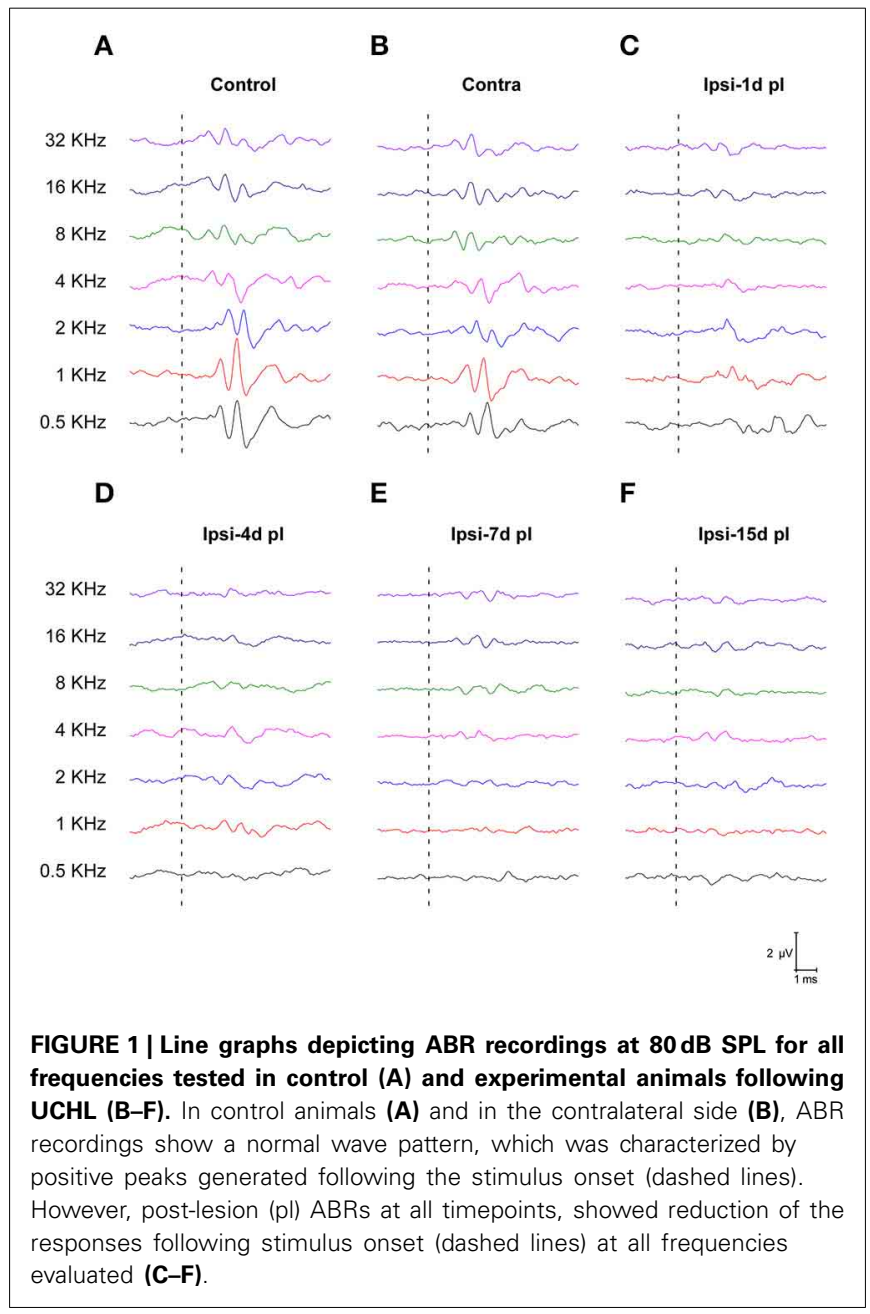

the healthy and injured brain (Guthrie et al., 1995; Watt and Hobbs, 2000; Hanisch, 2002; Parish et al., 2002). Studies in different lesion models such as ischemia and traumatic brain injury have shown increased production of insulin-like growth factor 1 (IGF-1) and interleukin-1 $\beta$ (IL-1 $\beta$ ) by glial cells (Touzani et al., 1999; Rothwell and Luheshi, 2000; Hwang et al., 2004; Madathil et al., 2010). Particularly in the auditory system,

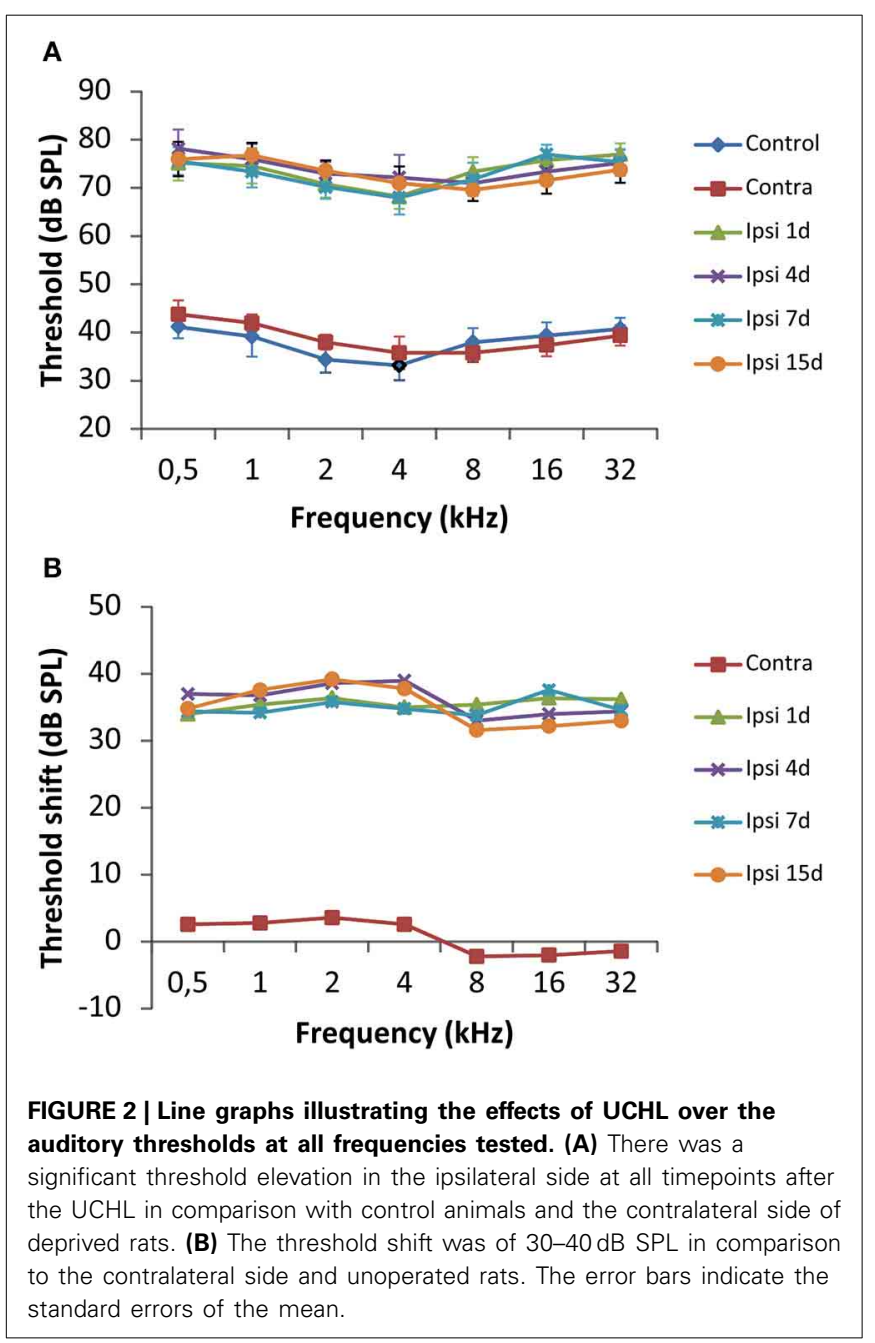

upregulation of IGF-1 and IL- $1 \beta$ levels occurs in neurons but not in either astrocytes or microglia within the ventral cochlear nucleus (AVCN) of adult rats at 1,7 , and $15 \mathrm{~d}$ after cochlear ablation (Fuentes-Santamaria et al., 2013). These findings support the idea that additional synthesis of IGF- 1 and IL- $1 \beta$ by glial cells is not essential to re-establish damaged auditory synaptic connections and that other molecular mediators might be 

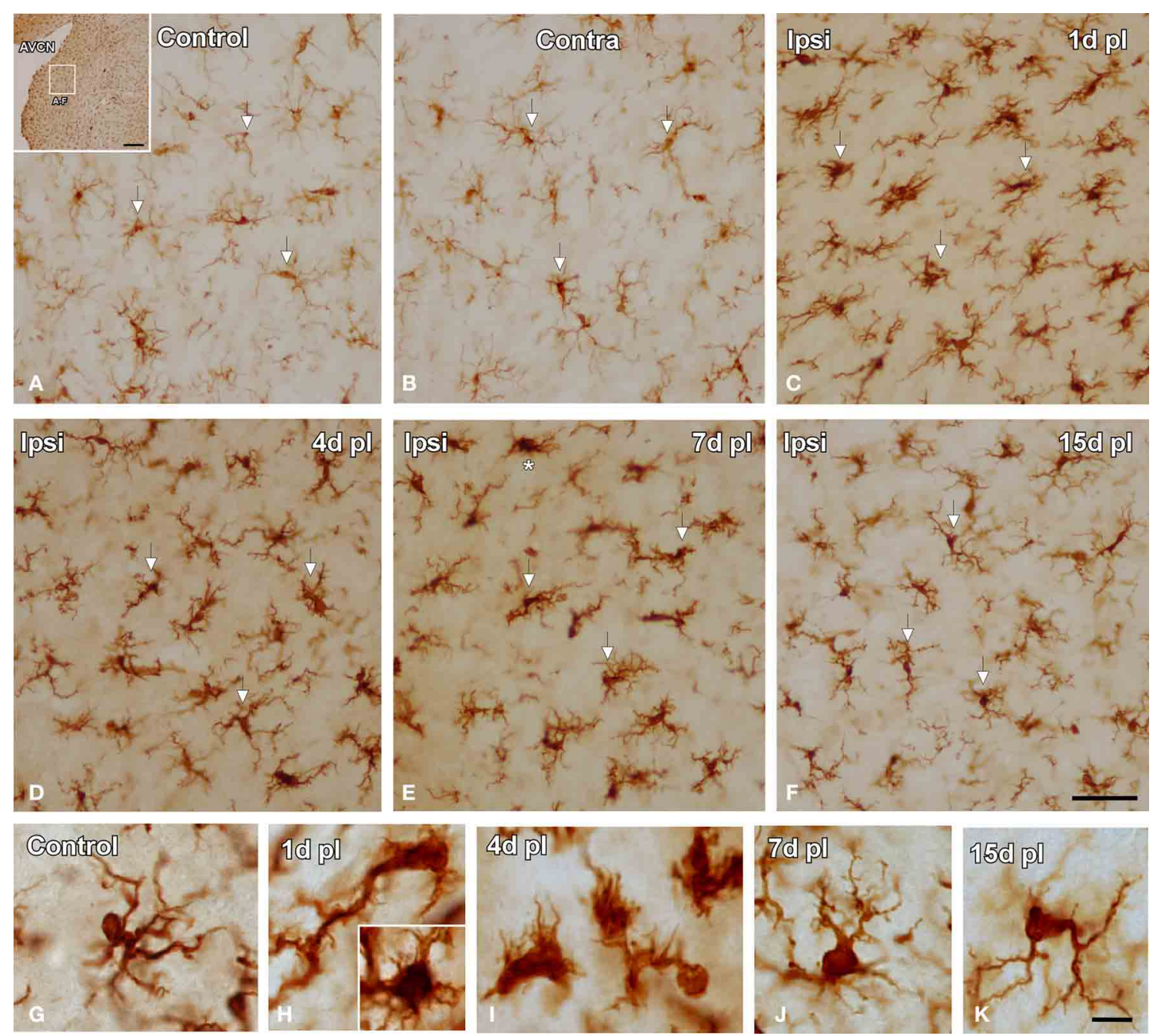

FIGURE 3 | Images depicting lba1 immunostaining in the AVCN in control and experimental animals. In the ipsilateral side, Iba1

immunostaining increased at $1 \mathrm{~d}$ post-lesion (arrows in C) and peaked around $4 \mathrm{~d}$ (arrows in $\mathbf{D}$ ) in comparison with the contralateral side and unoperated animals (arrows in A,B). Iba1 levels remained elevated at $7 d$ (arrows in $\mathbf{E}$ ) and decreased at 15d (arrows in $\mathbf{F}$ ) post-lesion. The morphological features of these cells are shown in G-K. Particularly at 7d post-lesion, activated microglial cells assumed very diverse phenotypes (compare asterisk and arrows in $\mathbf{E}$ ). The inset in A indicates the location of the AVCN, and the square box indicates the approximate locations of the fields represented in $\mathbf{A}-\mathbf{F}$. Scale bar $=250 \mu \mathrm{m}$ in $\mathbf{A} ; 50 \mu \mathrm{m}$ in $\mathbf{F} ; 10 \mu \mathrm{m}$ in $\mathrm{K}$. involved in this process. One possible candidate is neurotrophin3 (NT-3), a neurotrophic factor expressed in the adult and postnatal auditory system (Hafidi, 1999; Tierney et al., 2001). Apart from its role as a survival factor that, when injected into the cochlea, increases the survival of spiral ganglion neurons after deafness (Wise et al., 2011), NT-3 also participates in the reestablishment of lost synaptic connections. Supporting this concept, increases in NT-3 levels have been found in adult guinea pigs at $7 \mathrm{~d}$ following unilateral cochlear removal, a time point at which degeneration and synaptogenesis processes take place in the cochlear nucleus (Suneja et al., 2005). It is not known, however, whether NT-3 is dynamically expressed in glial cells after auditory lesions like unilateral conductive hearing loss (UCHL).
In addition to these changes, investigations in several species have provided insights into the role that reactive astrocytes might play in restoring synaptic homeostasis after sensorineural hearing loss (Lurie and Rubel, 1994; De Waele et al., 1996; Insausti et al., 1999; Lurie and Durham, 2000; Campos-Torres et al., 2005). Particularly in the cochlear nucleus, recent findings indicate that after cochlear ablation astrocytic activation is delayed (24 h) and less persistent $(<30 \mathrm{~d})$ relative to microglial responses, which appear earlier $(16 \mathrm{~h})$ and last longer (>90d) (Fuentes-Santamaria et al., 2012). These observations support the idea that although these non-neuronal elements have different temporal patterns of activation, they both are implicated in reestablishing synaptic function following deafness. In the present study, we interrupted the conduction of sound from the middle ear to the inner ear to 
A

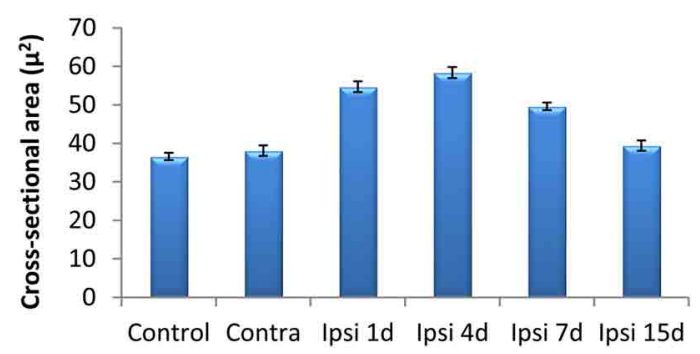

C

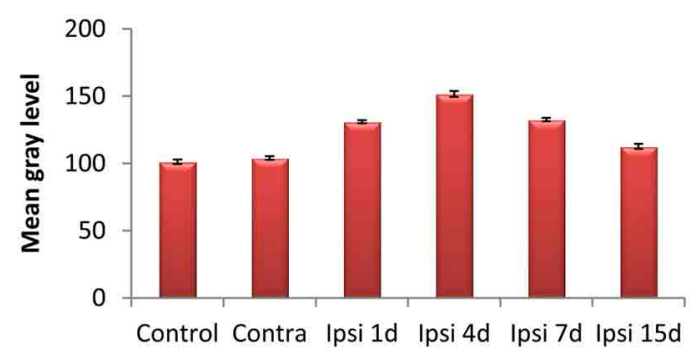

E

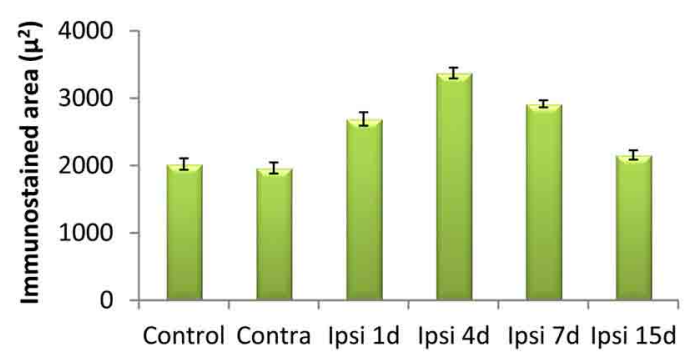

FIGURE 4 | Bar graphs showing the mean cross-sectional areas of lba1 immunostained cells $(A, B)$, the mean gray levels of the immunostaining $(C, D)$ and the immunostained areas $(E, F)$ in the AVCN of control and deprived animals. These three indexes were significantly increased at 1, 4,
B

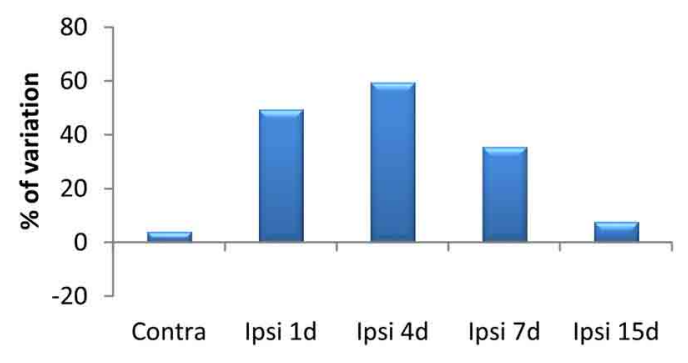

D

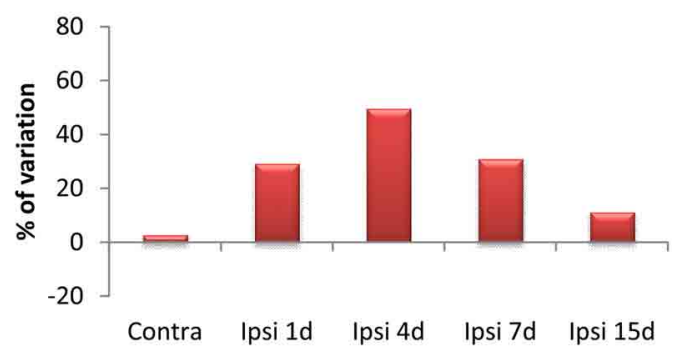

F

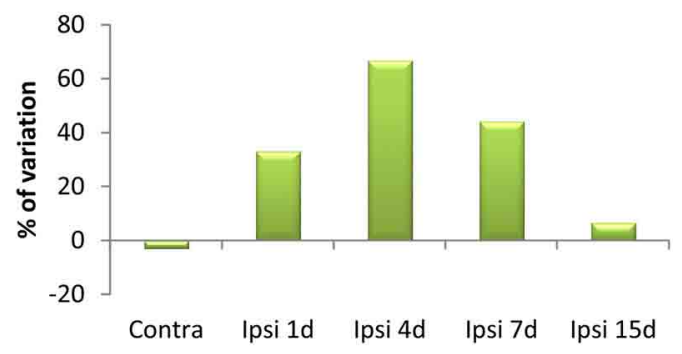

and $7 \mathrm{~d}$ but not at $15 \mathrm{~d}$ after ossicle removal in comparison with the contralateral side and unoperated animals. The percentages of variation for each quantitative index are shown in $\mathbf{B}, \mathbf{D}, \mathbf{F}$. The error bars indicate the standard errors of the mean. assess whether or not glial cells express NT-3 and contribute to the recovery of synaptic deficits associated with UCHL.

\section{MATERIALS AND METHODS ANIMALS}

All animal protocols were approved by the Institutional Animal Care and Use Committee at the University of Castilla-La Mancha (Permit Number: PR-2013-02-03). These protocols were in accordance with the guidelines of the European Communities Council (Directive 2010/63/EU) and current national legislation (R.D. 53/2013; Law 32/2007) for the care and use of research animals. For light and confocal microscopy, 16 experimental and 4 agematched unmanipulated control rats were used. An additional group of 12 experimental and 3 age-matched unmanipulated control rats was used for electron microscopy. Two month-old female adult rats were used for all experiments. Following the surgical procedure, the experimental animals survived for 1, 4, 7 , or $15 \mathrm{~d}$.

\section{AUDITORY BRAINSTEM RESPONSES (ABR)}

Animals were anesthetized with isofluorane (4\% for induction, $1.5-2 \%$ for maintenance with a $1 \mathrm{~L} / \mathrm{min} \mathrm{O} 2$ flow rate) and placed in a sound-attenuating electrically shielded booth (Eymasa/Incotron S.L., Barcelona, Spain) which was located inside a sound-attenuating room. Subdermal needle electrodes (Rochester Electro-Medical, Tampa, FL, USA) were placed at the vertex (positive) and under the right (negative) and left (ground) ears. The stimulation and recording were performed with a Tucker-Davis (TDT) BioSig System III (TuckerDavis Technologies, Alachua, FL, USA). As previously reported (Alvarado et al., 2012, 2014), the ABR recordings were performed the day before the surgical procedure and at the end of 
Table 2 | lba1 immunostaining in the AVCN in control and experimental animals.

\begin{tabular}{|c|c|c|c|c|}
\hline & & $\operatorname{CSA}\left(\mu \mathrm{m}^{2}\right)$ & MGL & ISA $\left(\mu \mathbf{m}^{2}\right)$ \\
\hline \multirow{7}{*}{ 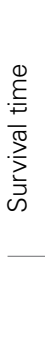 } & Control (1) & $36.6 \pm 0.9$ & $101.2 \pm 1.6$ & $2021.9 \pm 83.3$ \\
\hline & Contra (2) & $38.1 \pm 1.4$ & $104.1 \pm 1.3$ & $1962.9 \pm 84.4$ \\
\hline & $1 d(3)$ & $54.7 \pm 1.4$ & $130.9 \pm 1.1$ & $2692.3 \pm 99.3$ \\
\hline & $4 d(4)$ & $58.4 \pm 1.5$ & $151.6 \pm 2.2$ & $3373.4 \pm 79.2$ \\
\hline & $7 d(5)$ & $49.6 \pm 0.9$ & $132.6 \pm 1.2$ & $2916.1 \pm 51.8$ \\
\hline & $15 d(6)$ & $39.4 \pm 1.3$ & $112.6 \pm 1.9$ & $2156.4 \pm 67.6$ \\
\hline & ANOVA & $\begin{array}{c}F_{(5,954)}=54.8 \\
p<0.001\end{array}$ & $\begin{array}{c}F_{(5,174)}=141.6 \\
p<0.001\end{array}$ & $\begin{array}{c}F_{(5,174)}=51.42 \\
p<0.001\end{array}$ \\
\hline
\end{tabular}

\begin{tabular}{|c|c|c|c|c|}
\hline & & \multicolumn{3}{|c|}{ Significance levels } \\
\hline \multirow{15}{*}{ 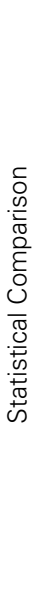 } & 1 vs. 2 & NS & NS & NS \\
\hline & 1 vs. 3 & $* * *$ & $* * *$ & *** \\
\hline & 1 vs. 4 & $* * *$ & $* * *$ & $* * *$ \\
\hline & 1 vs. 5 & $* * *$ & $* * *$ & $* * *$ \\
\hline & 1 vs. 6 & NS & $* *$ & NS \\
\hline & 2 vs. 3 & *** & $* * *$ & *** \\
\hline & 2 vs. 4 & $* * *$ & $* * *$ & *** \\
\hline & 2 vs. 5 & $* * *$ & $* * *$ & $* * *$ \\
\hline & 2 vs. 6 & NS & * & NS \\
\hline & 3 vs. 4 & NS & $* * *$ & *** \\
\hline & 3 vs. 5 & NS & NS & NS \\
\hline & 3 vs. 6 & $* * *$ & $* * *$ & ** \\
\hline & 4 vs. 5 & $* * *$ & $* * *$ & $* * *$ \\
\hline & 4 vs. 6 & *** & $* * *$ & $* * *$ \\
\hline & 4 vs. 6 & $* * *$ & $* * *$ & $* * *$ \\
\hline
\end{tabular}

Values are means \pm standard errors. CSA, Cross-sectional area of Iba1 immunostained cells; MGL, Mean gray level of Iba 1 immunostaining; ISA, Immunostained area of Iba1. ${ }^{*} p<0.05 ;{ }^{* *} p<0.01 ;{ }^{* * *} p<0.001 ; N S$, No significant.

each survival time. The stimuli were digitally generated using the SigGenRP software (Tucker-Davis Technologies) and the RX6 Piranha Multifunction Processor hardware (Tucker-Davis Technologies) and consisted of $5 \mathrm{~ms}$ rise/fall time tones, with no plateau and a $\cos 2$ envelope, delivered at 20/secat different frequencies across 7 octaves, from 0.5 to $32 \mathrm{kHz}$. They were delivered monaurally (right ear) using an EDC1 electrostatic speaker driver (Tucker-Davis Technologies) and the EC1 electrostatic speaker (Tucker-Davis Technologies) which was placed into the external auditory meatus of the rat. Prior to the experiments, stimuli were calibrated using the SigCal software (Tucker-Davis Technologies) and the ER-10B+ low noise microphone system (Etymotic Research Inc, Elk, Groove, IL, USA). The evoked potentials were filtered $(0.3-3.0 \mathrm{kHz})$, averaged (500 waveforms) and stored for later analyses on a computer. Auditory thresholds, for each of the frequencies evaluated, were determined comparing the evoked activity, recorded in $5 \mathrm{~dB}$ steps descending from a maximum stimulus intensity of $80 \mathrm{~dB}$ SPL, with the background activity measured before the stimulus onset. Auditory thresholds were defined as the stimulus intensity that evoked waves with a peak-to-peak voltage greater than 2 standard deviations above the background activity
(Cediel et al., 2006; Garcia-Pino et al., 2010; Alvarado et al., 2012, 2014).

\section{SURGICAL PROCEDURE FOR UNILATERAL CONDUCTIVE HEARING LOSS}

All surgical procedures were performed under aseptic conditions and unilaterally on the right ear. Rats were anesthetized with isofluorane as indicated above. Once the skin behind the ears was shaved, a retroauricular incision was made in order to identify the external auditory canal, which was followed to the tympanic membrane. Using fine forceps, the tympanic membrane was punctured and the malleus and incus were removed. During the surgical procedure a heating pad was used to maintain normal body temperature and recovery from anesthesia. Once awake, animals were returned to their cages and maintained with free access to food and water for the survival period.

\section{PRIMARY ANTIBODIES}

The antibodies used in this study are listed in Table 1. Glial and neuronal antibodies included (1) mouse anti-glial fibrillary acidic protein (GFAP); (2) rabbit anti-glial fibrillary acidic protein (GFAP); (3) ionized calcium binding adaptor molecule 1 (Iba1); (4) mouse anti-CD11b; (5) mouse anti-neuronal nuclei $(\mathrm{NeuN})$ and (6) rabbit anti-neurotrophin-3 (NT-3).

\section{IMMUNOPEROXIDASE STAINING PROCEDURE}

After the appropriate post-operative survival time, control and experimental rats were anesthetized with an intraperitoneal injection of ketamine $(100 \mathrm{mg} / \mathrm{Kg})$ and xylazine $(5 \mathrm{mg} / \mathrm{Kg})$ and perfused transcardially with $0.9 \%$ saline wash followed by a fixative solution of $4 \%$ paraformadehyde in $0.1 \mathrm{M}$ phosphate buffer $(\mathrm{PB}, \mathrm{pH} 7.3)$. The brains were removed from the cranium, and crioprotected for $48 \mathrm{~h}$. Frozen sections $40 \mu \mathrm{m}$ thick were cut on a sliding microtome in a coronal plane. After blocking for $1 \mathrm{~h}$ in a solution containing $10 \%$ normal goat serum (NGS) diluted in Tris-buffered saline (TBS, pH 7.4) with $0.2 \%$ Triton X-100 (TBS-Tx $0.2 \%$ ), sections were subsequently incubated overnight at $4^{\circ} \mathrm{C}$ in the same buffer solution with polyclonal primary antibodies for either Ibal or GFAP or NT-3 (Table 1). The next day, sections were washed in a TBS-Tx $0.2 \%$ solution and incubated for $2 \mathrm{~h}$ at room temperature (RT) in biotinylated goat anti-rabbit secondary antibody (1:200, Vector Laboratories, Burlingame, CA, USA). Then, after several rinses in TBS-Tx $0.2 \%$, sections were incubated in an avidin-biotinylated peroxidase complex $(\mathrm{ABC})$ and rinsed in TBS. Sections were then exposed to $3-3^{\prime}$ dimanobenzidine (DAB) as the chromogenic peroxidase substrate. Care was taken to ensure that incubation times in DAB were identical across control and experimental cases. Finally, the sections were washed thoroughly, mounted on gelatin-coated slides, air-dried, dehydrated in progressive ethanol solutions, cleared in xylene, and coverslipped with Cytoseal ${ }^{\circledR}$ (Stephens Scientific, Wayne, NJ, USA). Three sets of control experiments were performed to test the specificity of immunohistochemistry detection system: (1) omission of the primary antibody by replacement with TBSBSA; (2) omission of secondary antibodies; and (3) omission of $\mathrm{ABC}$ reagent. No immunostaining was detected under these conditions. 

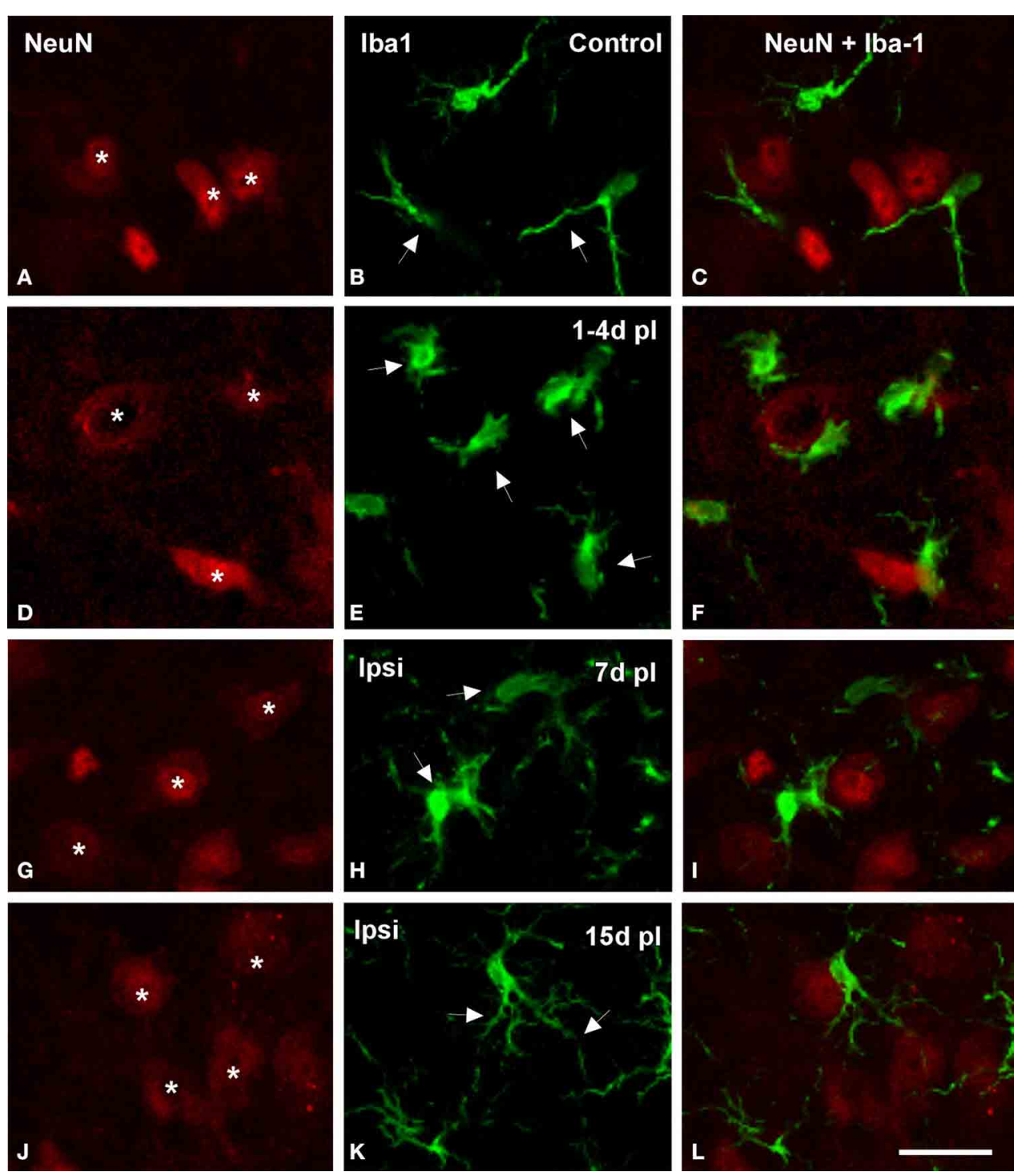

FIGURE 5 | Confocal images showing appositions between microglial cells and neurons in the ipsilateral AVCN in control and deprived rats. In control rats, microglial cells with round or fusiform cell bodies and ramified processes were in close proximity to cochlear nucleus neurons (arrows and asterisks in $\mathbf{A}-\mathbf{C}$ ). The frequency of these appositions was particularly increased at 1 and $4 \mathrm{~d}$ after the lesion, when enlarged microglial cell bodies with short processes were frequently observed opposing the soma and dendrites of cochlear nucleus neurons in the affected side (arrows and asterisks in D-F). At later survival times after ossicle removal, the occurrence of these cellular contacts decreased (arrows and asterisks in $\mathbf{G}-\mathbf{L}$ ). Scale bar $=25 \mu \mathrm{m}$ in $\mathbf{L}$.

\section{DOUBLE IMMUNOFLUORESCENCE LABELING}

Sections were rinsed four times in TBS-Tx $0.2 \%$ and blocked for $1 \mathrm{~h}$ in the same buffer solution containing 10\% NGS. Then, sections were incubated incubated overnight with one of the following mixtures of primary antibodies: (1) NeuN and Iba1; (2) NeuN and GFAP; (3) NT-3 and CD11b; and (4) NT-3 and GFAP primary antibodies. Following four $15 \mathrm{~min}$ rinses in TBS-Tx $(0.2 \%)$, sections were incubated in the corresponding cocktail of fluorescently labeled secondary antibodies for $2 \mathrm{~h}$ at room temperature (1:200, anti-mouse antibodies conjugated to Alexa 594 (A-11005) and anti-rabbit antibodies conjugated to Alexa 488 (A-11008; Molecular Probes, Eugene, OR, USA) and after several rinses in TBS, they were mounted, counterstained with
DAPI, coverslipped, and maintained overnight at $4^{\circ} \mathrm{C}$. Sections were examined with a laser scanning confocal microscope (LSM 710; Zeiss, Germany) with excitation laser lines at 405, 488, and $594 \mathrm{~nm}$, using the ZEN 2009 Light Edition software. Maximum intensity projections of a $\mathrm{z}$-stack were generated. For each dye, optical sections every $2.5 \mu \mathrm{m}$ through the thickness of the tissue were captured with a 63X Plan Apo oil-immersion objective (1.4 NA), at fixed camera gain, pinhole size, and laser intensity. Then, images were merged and saved as TIFF files.

\section{ELECTRON MICROSCOPY IMMUNOCYTOCHEMISTRY}

Animals were anesthetized as described above and perfused transcardially with $0.9 \%$ saline wash followed by a fixative 

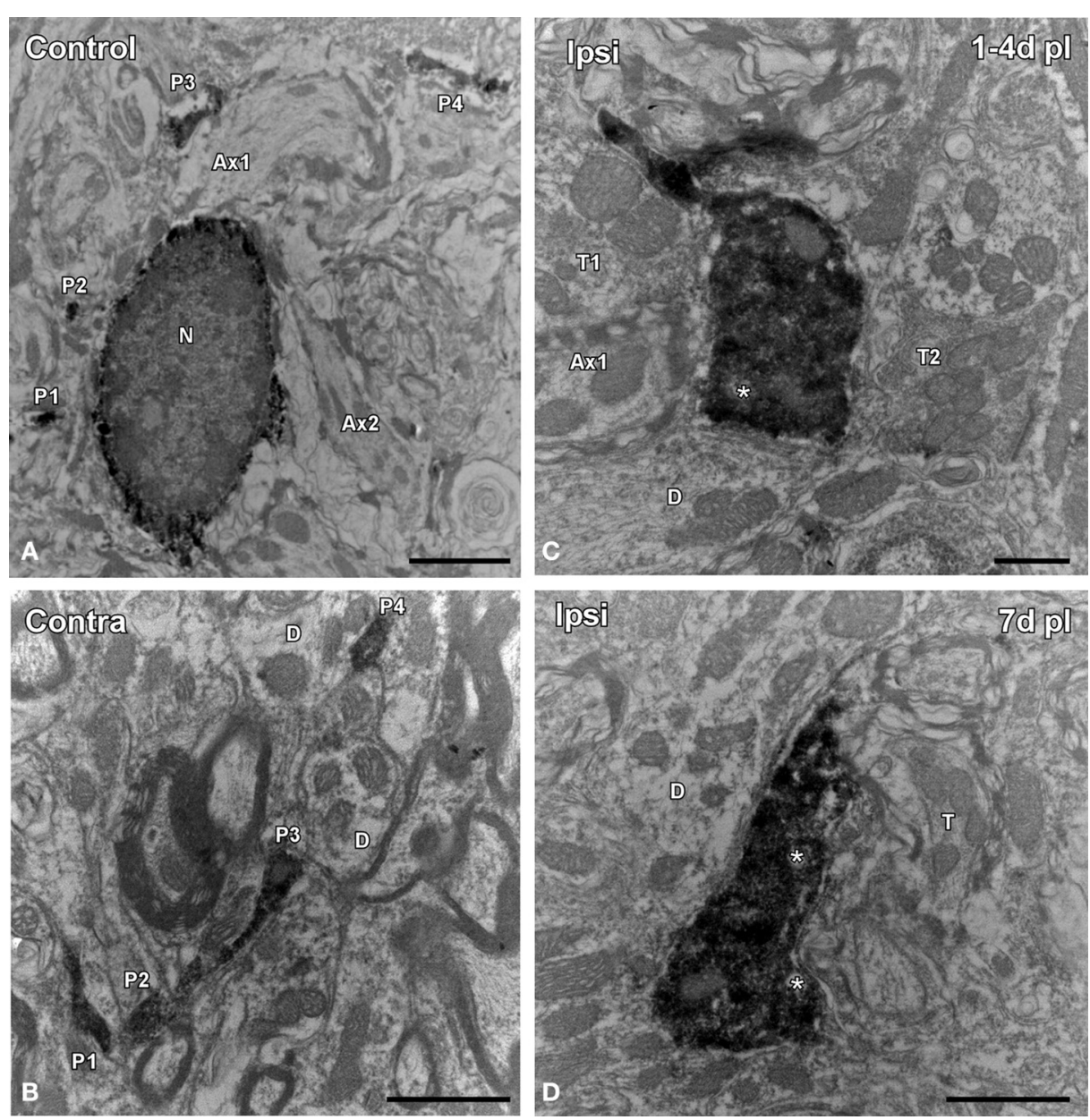

FIGURE 6 | Electron microscopy images showing the ultrastructural features of lba1 immunostained cells in the ipsilateral AVCN in comparison to the contralateral side and control animals. In the control condition (A) and in the contralateral side (B) to the lesion, microglial cells have a nucleus with dense heterochromatin, a cytoplasm with numerous organelles and inclusion bodies. Note that multiple labeled processes (P1-P4) of different sizes and shapes are scattered in the neuropil. Between 1 and $7 \mathrm{~d}$ following unilateral ossicle removal, these cells have a larger cytoplasm and thicker processes rich in vacuoles and multi-vesicular bodies (asterisks) that were seen contacting nearby synaptic elements (C,D). $A \times 1-A \times 2$, axons; $\mathrm{D}$, dendrite; N, nucleus; P1-P4, processes; T, terminal. Scale bar $=2 \mu \mathrm{m}$ in $\mathbf{A}$; $1 \mu \mathrm{m}$ in $\mathbf{B}, \mathbf{D} ; 0.5 \mu \mathrm{m}$ in $\mathbf{C}$. perfusion of $4 \%$ paraformadehyde and $0.5 \%$ glutaraldehyde in $0.1 \mathrm{M} \mathrm{PB}, \mathrm{pH}$ 7.3. After fixation, the brains were removed, and sectioned at $40 \mu \mathrm{m}$ on a vibratome in the coronal plane. After several washes in PBS, sections were pre-incubated for $1 \mathrm{~h}$ in $10 \%$ NGS and then incubated overnight at $4^{\circ} \mathrm{C}$ with either Ibal or GFAP polyclonal antibodies diluted in PBS. The following day, after several rinses in PBS, sections were incubated in a dilution of anti-rabbit secondary antibody (1:200) for $2 \mathrm{~h}$ at RT and after several rinses they were incubated in $\mathrm{ABC}$ for $1 \mathrm{~h}$. Peroxidase activity was visualized with a nickelintensified $\mathrm{DAB}$ reaction to produce a black reaction product. Sections containing the cochlear nucleus were post-fixed with osmium tetraoxide ( $1 \%$ in $0.1 \mathrm{M} \mathrm{PB}$ ) for $1 \mathrm{~h}$, block-stained with $1 \%$ uranyl acetate for $30 \mathrm{~min}$, dehydrated in graded series of ethanol and embedded in Durcupan (Fluka) resin. Thin sections $(\sim 75 \mathrm{~nm})$ in the silver-gold range were cut on an ultramicrotome (Reichert Ultracut E, Leica, Austria) and collected on 200-mesh copper grids. Tissue was observed using a Jeol-1010 electron microscope.

\section{MEASUREMENTS OF THE CROSS-SECTIONAL AREA OF IBA1 IMMUNOSTAINED CELLS}

As glial cells could modify their phenotype in response to minor changes in their cellular environment, the cross-sectional area, was used as an indicator of possible changes in the soma size of glial cells at the different time points after the UCHL. The cross-sectional area of Ibal immunostained cells in both control and experimental animals was measured using the public domain image analysis software Scion Image for Windows (Scion, Frederick, MD; $\mathrm{v}$ beta 4.0.2). Using a $60 \times$ objective, three fields $\left(25.16 \times 10^{3} \mu \mathrm{m}^{2}\right.$; dorsal, middle and ventral) were sampled randomly in every fourth section throughout the rostrocaudal extent of the cochlear nucleus. Only cells with a well-defined cell body, 

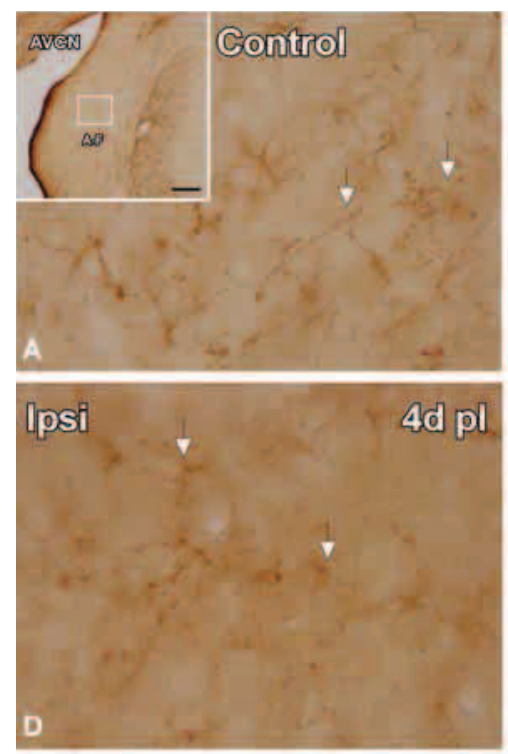

G

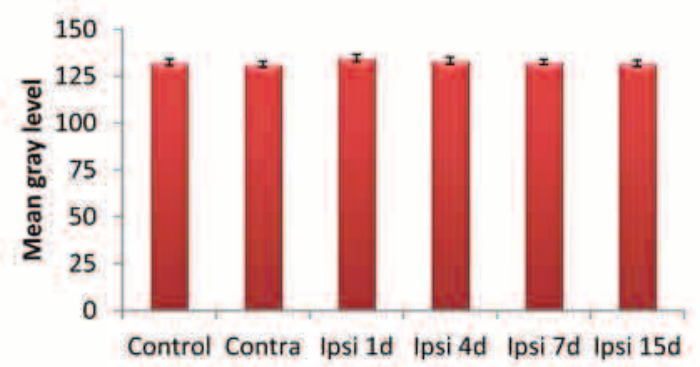

I

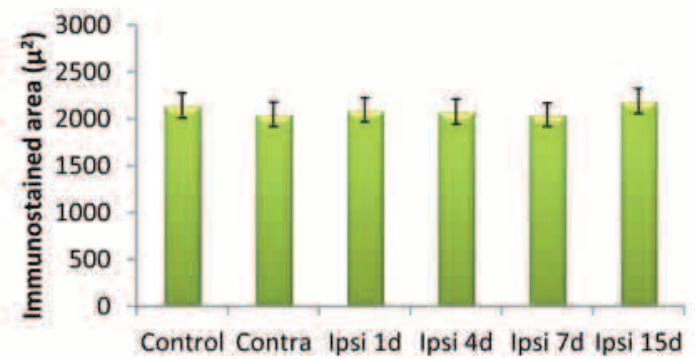

FIGURE 7 | Images depicting GFAP immunostaining in the AVCN in control rats and following unilateral ossicle removal. GFAP immunostaining in the ipsilateral side did not change at any survival time after the lesion (C-F) in comparison with the contralateral side (B) and unoperated (A) animals. Bar graphs show the mean gray levels of GFAP immunostaining $(\mathbf{G}, \mathbf{H})$ and the immunostained areas $\mathbf{( I , J ) . ~ W h e n ~ t h e ~ t w o ~ i n d e x e s ~ w e r e ~ e v a l u a t e d ~ i n ~ t h e ~}$
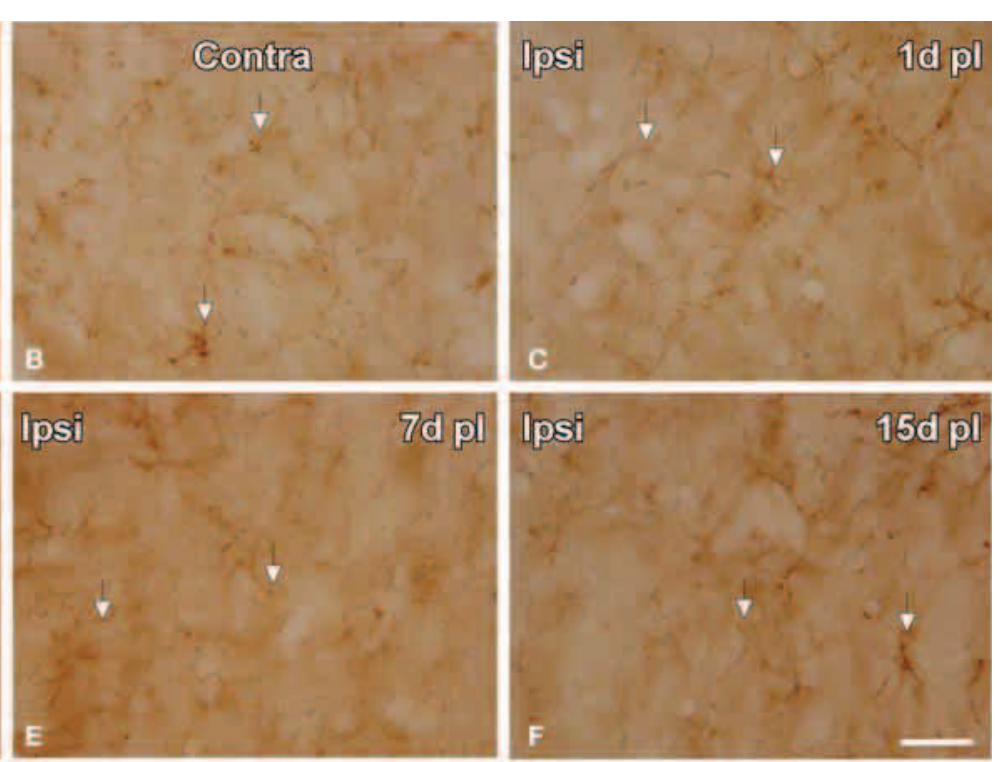

H

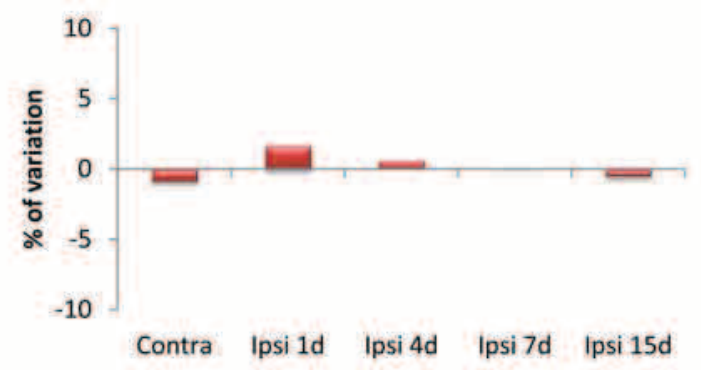

J

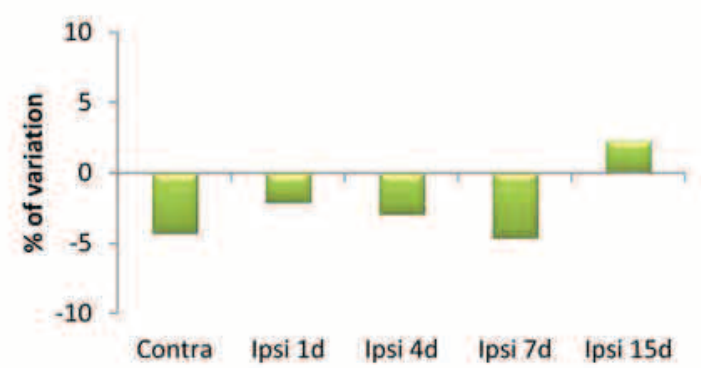

ipsilateral cochlear nucleus of unilaterally deprived animals at all the timepoints studied, there were no differences when compared with the contralateral side and unoperated animals. The error bars indicate the standard errors of the mean. The inset in A indicates the location of the AVCN, and the square box indicates the approximate locations of the fields represented in $\mathbf{A}-\mathbf{F}$. Scale bar $=250 \mu \mathrm{m}$ in $\mathbf{A} ; 25 \mu \mathrm{m}$ in $\mathbf{F}$. nucleus and nucleolus were measured and included in the analysis.

\section{ANALYSIS OF THE IMMUNOSTAINING}

Immunostained sections from control and experimental animals were examined with bright field illumination using a Nikon
Eclipse photomicroscope with a $40 \times$ objective and images captured with a DXM 1200C digital camera attached to the microscope. Color images of each field were digitized and the resultant 8 -bit image contained a grayscale of pixel intensities that ranged from 0 (white) to 255 (black). As previously described (FuentesSantamaria et al., 2003, 2005, 2007; Alvarado et al., 2004, 2005, 
Table 3 | GFAP immunostaining in the AVCN in control and experimental animals.

\begin{tabular}{|c|c|c|c|}
\hline & & MGL & ISA $\left(\mu \mathbf{m}^{2}\right)$ \\
\hline \multirow{7}{*}{ 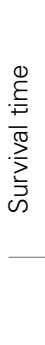 } & Control (1) & $132.5 \pm 1.9$ & $2141.2 \pm 134.2$ \\
\hline & Contra (2) & $131.3 \pm 1.6$ & $2049.3 \pm 131.1$ \\
\hline & $1 d(3)$ & $134.7 \pm 2.0$ & $2095.8 \pm 126.6$ \\
\hline & $4 d(4)$ & $133.3 \pm 1.9$ & $2078.3 \pm 135.3$ \\
\hline & $7 d(5)$ & $132.5 \pm 1.5$ & $2042.5 \pm 126.3$ \\
\hline & $15 d(6)$ & $131.8 \pm 1.7$ & $2191.1 \pm 133.9$ \\
\hline & ANOVA & $\begin{array}{c}F_{(5,114)}=0.4 \\
\text { NS }\end{array}$ & $\begin{array}{c}F_{(5,114)}=0.2 \\
N S\end{array}$ \\
\hline
\end{tabular}

\begin{tabular}{|c|c|c|c|}
\hline & \multicolumn{3}{|c|}{ Significance levels } \\
\hline \multirow{15}{*}{ 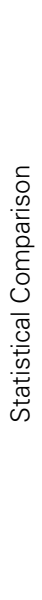 } & 1 vs. 2 & NS & NS \\
\hline & 1 vs. 3 & NS & NS \\
\hline & 1 vs. 4 & NS & NS \\
\hline & 1 vs. 5 & NS & NS \\
\hline & 1 vs. 6 & NS & NS \\
\hline & 2 vs. 3 & NS & NS \\
\hline & 2 vs. 4 & NS & NS \\
\hline & 2 vs. 5 & NS & NS \\
\hline & 2 vs. 6 & NS & NS \\
\hline & 3 vs. 4 & NS & NS \\
\hline & 3 vs. 5 & NS & NS \\
\hline & 3 vs. 6 & NS & NS \\
\hline & 4 vs. 5 & NS & NS \\
\hline & 4 vs. 6 & NS & NS \\
\hline & 5 vs. 6 & NS & NS \\
\hline
\end{tabular}

Values are means \pm standard errors. MGL, Mean gray level of GFAP immunostaining; ISA, Immunostained area of GFAP; NS, No significant.

2007), the densitometric procedure for the evaluation of the immunostaining was performed by using the public domain image analysis software Scion Image for Windows. Cochlear nucleus subdivisions were defined in accordance with previous terminology (for review, see Cant and Benson, 2003). The analysis of Iba1, GFAP and NT-3 immunostaining was performed in 6 coronal sections, $120 \mu \mathrm{m}$ apart, through the rostrocaudal extent of the AVCN. In each section, three fields $\left(55.25 \times 10^{3} \mu \mathrm{m}^{2}\right.$ dorsal, middle and ventral) were sampled using a $40 \times$ objective. In order to perform an appropriate comparison of the immunostaining among cases, a macro was designed to process and analyze the captured images (Alvarado et al., 2004). Briefly, images were normalized by using an algorithm, based on the signal-to noise ratio that normalizes each pixel, adjusting the grayscales range of the image. Following normalization, the threshold level was set as two standard deviations above the mean gray level of the field and immunostained cells exceeding this threshold were identified as labeled. Additionally, as both the intensity and area of the immunostaining could be affected by changes in activity (Caicedo et al., 1997), the mean gray level of the immunostaining and the immunostained area were used as indicators of changes in protein levels (Winsky and Jacobowitz, 1995; Benson et al., 1997).
It has been demonstrated that the intensity of the immunostaining is related to antigen concentration (Huang et al., 1996; Yao and Godfrey, 1997). Therefore, the mean gray level was used as an indirect measure of intracellular protein levels within cells after UCHL providing a general estimation of the effect of the unilateral deprivation on the immunostaining of neurons and glia. Additionally, the immunostained area was used as an indicator of the area occupied by microglial cells and astrocytes at each survival time in comparison to control rats. It was calculated as the summed area of all profiles (cells and processes) labeled above the threshold in each field.

\section{PREPARATION OF FIGURES AND STATISTICAL ANALYSIS}

Photoshop (Adobe v5.5) and Canvas (Deneba v6.0) were used to adjust size, brightness and contrast of publication images. All the data were expressed as means \pm standard error of the mean. Comparisons among groups were analyzed statistically using the one-factor analysis of variance and the Scheffe's post-hoc analysis to evaluate the effect of the survival time after unilateral conductive hearing loss over the immunostaining in the cochlear nucleus. Statistical significance was set at a level of $p<0.05$.

\section{RESULTS}

\section{AUDITORY BRAINSTEM RESPONSES (ABR)}

To evaluate alterations in auditory function following UCHL, $A B R$ recordings were performed in rats before (pre-lesion ABR) and after (post-lesion ABR) unilateral ossicle removal for each of the time points described in the Materials and Methods Section. Similar to the control condition, the pre-lesion recordings showed a distinctive wave pattern characterized by four to five positive peaks generated after a stimulus (Figure 1A). Meanwhile, the post-lesion ABR in the ear ipsilateral to the lesion (Figures 1C-F) showed differences in the wave amplitudes at all the frequencies tested when compared to the contralateral side (Figure 1B) and control animals (Figure 1A). Experimental rats had significant thresholds elevations at all frequencies and time points studied after UCHL which were indicative of decreased activity in the ipsilateral auditory nuclei (Figure 2).

\section{MICROGLIAL RESPONSE TO UCHL}

In the control condition and in the side contralateral to the lesion, microglial cells in the AVCN had round or oval cell bodies and long ramified processes (Figures 3A,B,G). A microglial reaction in the ipsilateral AVCN of experimental animals was first detectable 1 day after the lesion, at which time glial cells had larger cell bodies along with thicker and less branched processes than resting microglia (Figures $\mathbf{3 C}, \mathbf{H}$ ). At $4 \mathrm{~d}$ post-lesion, microglial expression was maximal (Figures 3D,I) when compared to that in the intact side (Figure 3B) and control (Figure 3A) animals. Cells were larger, darker and occupied a larger area when compared to those observed at $1 \mathrm{~d}$ post-lesion. These qualitative observations were confirmed by significant increases in their cross-sectional area, mean gray level of Ibal immunostaining and immunostained area (Figure 4; Table 2). At 7d post-lesion, glial cells displayed a remarkable heterogeneity in their morphology. Some cells had smaller cell bodies and longer processes (arrowheads in Figures 3E,J) while others had morphologies resembling those 

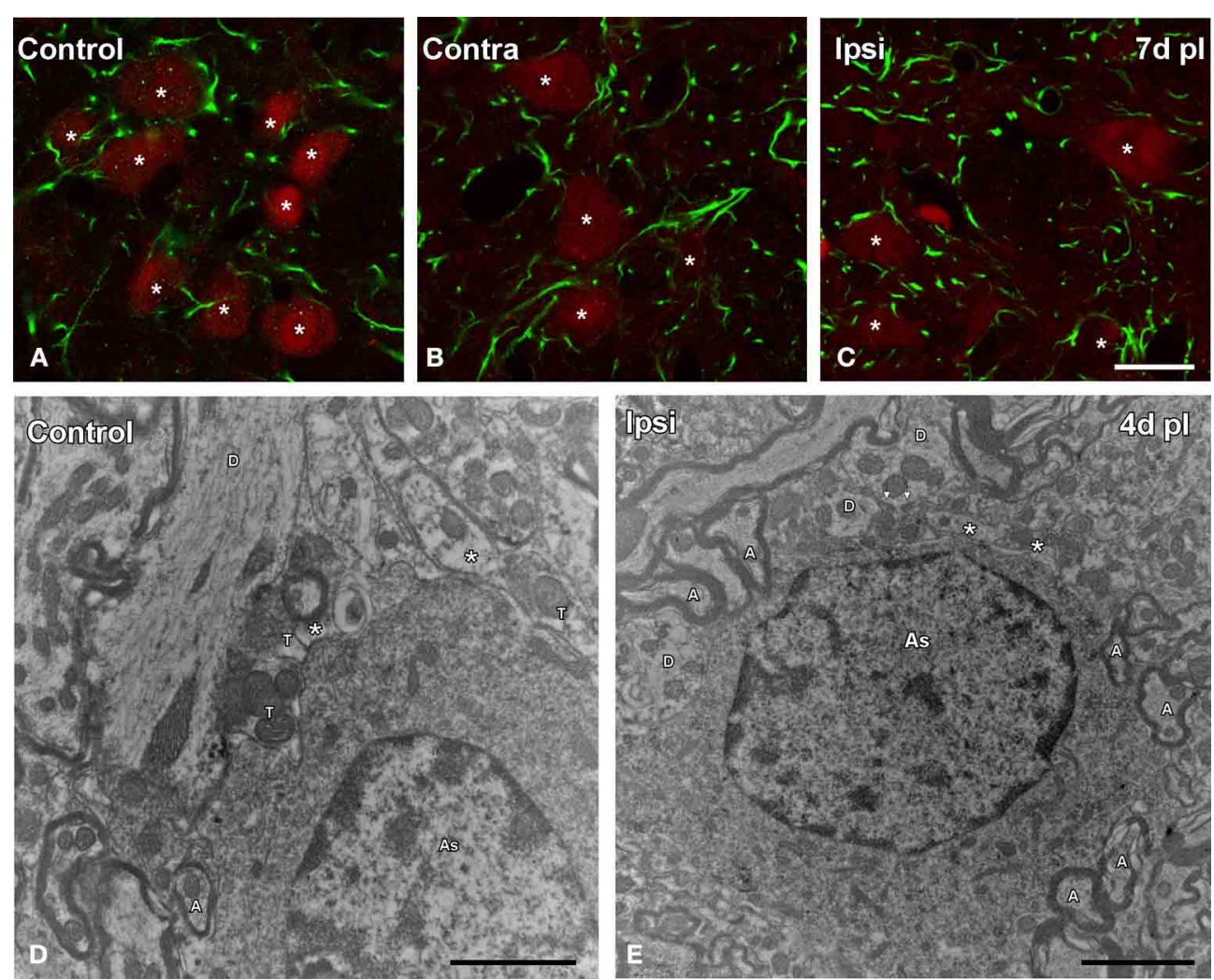

FIGURE 8 | Confocal and electron microscopy images illustrating appositions between astrocytes and cochlear nucleus neurons in control and deprived rats. Note that astrocytic processes were distributed in the neuropil or closely associated to cochlear nucleus neurons in control and deprived animals (A-C). The utrastructural characteristics of these cells in the cochlear nucleus are shown in $\mathbf{D , E}$. These macroglial cells were contacting with surrounding cellular elements of the neuropil in the control condition and after ossicle removal (asterisks in $\mathbf{D}, \mathbf{E}$ ). A, axon; As, astrocyte T, terminal; D, dendrite. Scale bar $=20 \mu \mathrm{m}$ in $\mathbf{C}$ (also applies to $\mathbf{A}, \mathbf{B}$ ); $1 \mu \mathrm{m}$ in D; $2 \mu \mathrm{m}$ in $\mathbf{E}$. seen at 1 and $4 \mathrm{~d}$ post-lesion (compare asterisk and arrows in Figure 3E). At this time point, the microglial cross-sectional area was significantly decreased when compared with the other survival time points. However, it was increased when compared with the unmanipulated side and control animals (Figures 3, 4; Table 2). Glial cells were still darkly immunostained as confirmed by significant decreases in the mean gray levels when compared with experimental animals at $4 \mathrm{~d}$ post-lesion, but no differences were found when compared with $1 \mathrm{~d}$ post-lesion animals (Figure 4; Table 2). At longer survival times (15d post-lesion), microglial cells adopted the typical ramified structure usually seen in the normal brain (Figures 3F,K, 4).

Microglial-neuronal appositions in the ipsilateral AVCN were predominantly observed at 1 and 4 d post-lesion (Figures 5D-F), when microglia assumed a more amoeboid phenotype (arrows in Figure 5E) and surrounded injured cochlear neurons (asterisks in Figure 5D). These close appositions were less frequently seen at day 7 (Figures 5G-I) and were almost absent at day 15 (Figures 5J-L) when microglial cells transformed into the ramified phenotype similar to that seen in the contralateral side and control animals (Figures 5A-C). The utrastructural features of Iba1 immunostained cells in the cochlear nucleus of control and experimental rats are shown in Figure 6. Iba1 immunostained microglial cells were identified by the presence of electron-dense DAB reaction product within their cell body cytoplasm and processes. In the control condition and the side contralateral to the lesion, microglial cells in the resting ramified state had a nucleus with dense heterochromatin packed against the nuclear membrane, a cytoplasm with numerous organelles and inclusion bodies and multiple labeled processes of different sizes and shapes in the neuropil (Shapiro et al., 2009; Figures 6A,B). In the ipsilateral AVCN of experimental animals, activated microglia was characterized by an enlarged cytoplasm and thicker processes rich in vacuoles and multi-vesicular bodies, which were observed surrounding neuronal processes and contacting nearby synaptic elements (Figures 6C,D).

\section{ASTROGLIAL RESPONSE TO UCHL}

GFAP immunostaining in unmanipulated animals was observed mostly as branched astroglial processes heterogeneously distributed through the AVCN (Figure 7A). Following UCHL, the morphology and staining features of astrocytes were similar to those observed in control animals (Figures 7A-F). Quantification of the mean gray levels and immunostained areas of GFAP immunostaining in experimental animals indicated that there were no differences at any survival time when compared to either 

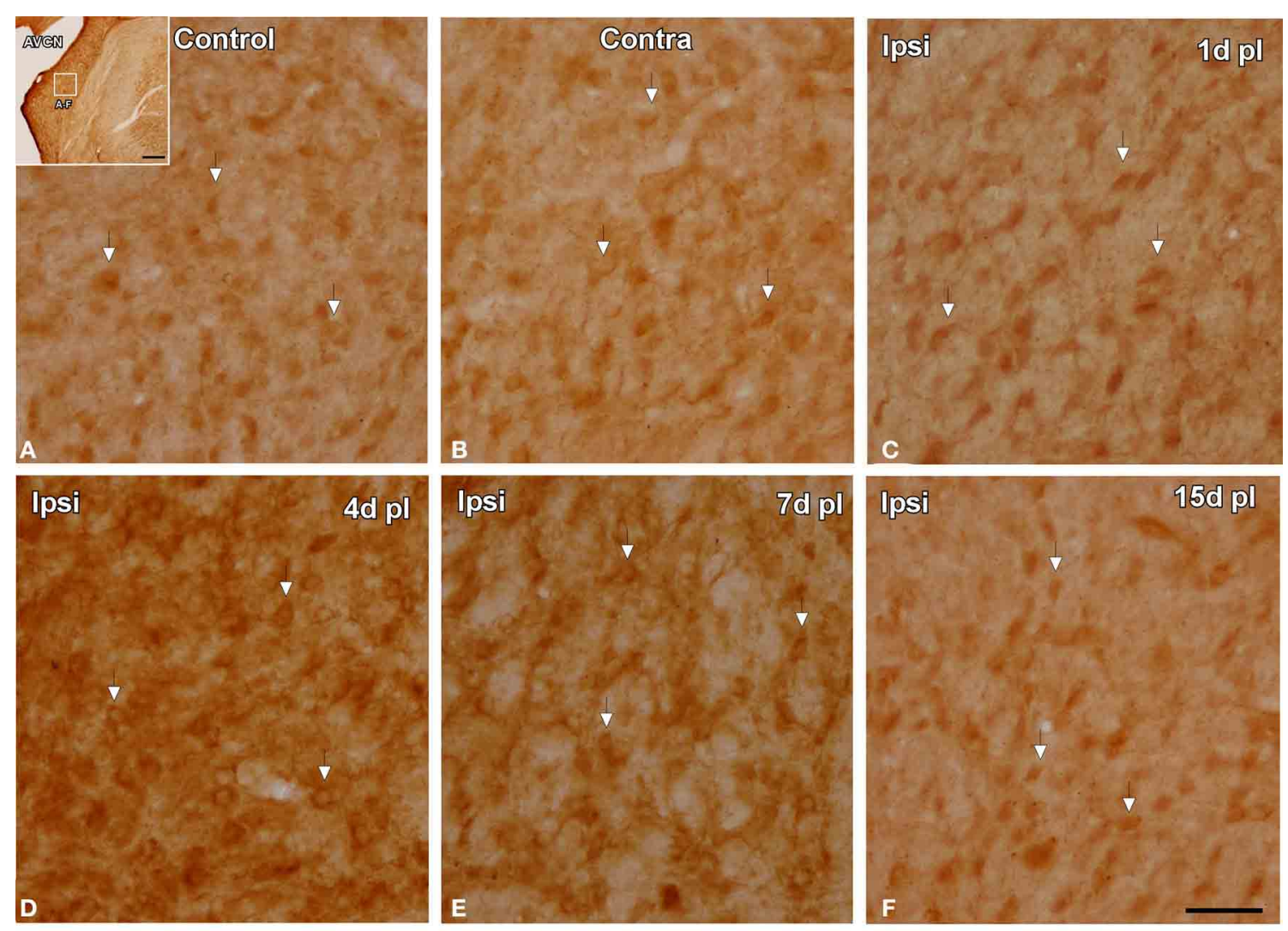

G

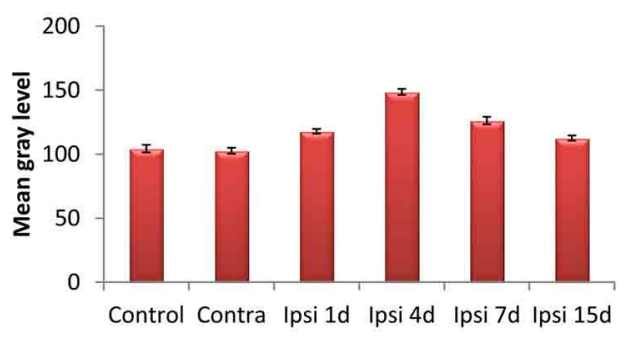

FIGURE 9 | Images depicting NT-3 immunostaining in the AVCN in control and deprived animals. In the ipisilateral side, the immunostaining increased at 1, 4, and $7 \mathrm{~d}$ post-lesion (arrows in $\mathbf{C}-\mathbf{E}$ ) in comparison with the contralateral side and unoperated animals (arrows in $\mathbf{A}, \mathbf{B}$ ). Note that NT-3 levels decreased at $15 \mathrm{~d}$ post-lesion in comparison to the other survival time

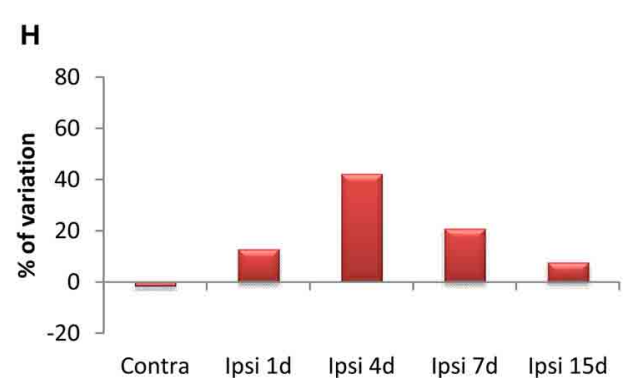

points (arrows in F). This upregulation was confirmed by significant increases in the mean gray level of the immunostaining at the above mentioned survival times $(\mathbf{G}, \mathbf{H})$. The inset in A indicates the location of the AVCN, and the square box indicates the approximate locations of the fields represented in $\mathbf{A}-\mathbf{F}$. Scale bar $=250 \mu \mathrm{m}$ in $\mathbf{A} ; 50 \mu \mathrm{m}$ in $\mathbf{F}$. the contralateral side or normal control animals (Figures 7G-J; Table 3). Similar to the control condition, astrocytic processess were found in the neuropil or closely associated with cochlear nucleus cell bodies at all the time points studied (Figures 8A-C). The utrastructural features of astrocytes in the AVCN of control and experimental rats are shown in Figures 8D,E. These macroglial cells contacted surrounding cellular elements in the neuropil (asterisks in Figures 8D,E)

\section{UPREGULATION OF NT-3 IMMUNOSTAINING FOLLOWING UCHL}

In control and experimental animals, NT-3 immunostaining was localized within the cell cytoplasm and also in the neuropil in the
AVCN (Figure 9). At 1, 4, and 7 d post-lesion (Figures 9C-E), immunostaining in the ipsilateral side was significantly increased compared to the contralateral side and to normal control animals (Figures 9A,B). These observations were corroborated by significant increases in the mean gray level of the immunostaining at the above mentioned survival times (Figures 9G,H; Table 4).

To determine whether glial cells expressed NT-3 following UCHL, double-labeling experiments with neuronal and glial markers were performed in both control and experimental animals. Few microglial cells (Figure 10) and astrocytes (Figure 11) colocalyzed with NT-3, demonstrating that neurons and nerve terminals are the main sources of NT-3 within the AVCN 
Table 4 | NT3 immunostaining in the AVCN in control and experimental animals.

\begin{tabular}{|c|c|c|}
\hline & & MGL \\
\hline \multirow{6}{*}{ 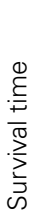 } & Control (1) & $104.3 \pm 2.9$ \\
\hline & Contra (2) & $102.7 \pm 2.3$ \\
\hline & $1 d(3)$ & $117.9 \pm 1.8$ \\
\hline & $4 d(4)$ & $148.6 \pm 2.3$ \\
\hline & $7 d(5)$ & $126.3 \pm 2.8$ \\
\hline & $15 d(6)$ & $112.6 \pm 2.0$ \\
\hline & ANOVA & $\begin{array}{c}F_{(5,144)}=50.8 \\
p<0.001\end{array}$ \\
\hline
\end{tabular}

\begin{tabular}{|c|c|c|}
\hline & & Significance levels \\
\hline \multirow{15}{*}{ 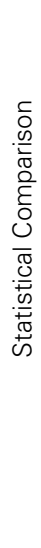 } & 1 vs. 2 & NS \\
\hline & 1 vs. 3 & $* *$ \\
\hline & 1 vs. 4 & $* * *$ \\
\hline & 1 vs. 5 & $* * *$ \\
\hline & 1 vs. 6 & NS \\
\hline & 2 vs. 3 & $* *$ \\
\hline & 2 vs. 4 & $* * *$ \\
\hline & 2 vs. 5 & $* * *$ \\
\hline & 2 vs. 6 & NS \\
\hline & 3 vs. 4 & $* * *$ \\
\hline & 3 vs. 5 & NS \\
\hline & 3 vs. 6 & NS \\
\hline & 4 vs. 5 & $* * *$ \\
\hline & 4 vs. 6 & $* * *$ \\
\hline & 5 vs. 6 & $* *$ \\
\hline
\end{tabular}

Values are means \pm standard errors. MGL, Mean gray level of NT3 immunostaining. ${ }^{*} p<0.05 ;{ }^{* *} p<0.01 ;{ }^{* * *} p<0.001 ; N S$, No significant.

(Figures 10, 11). The colocalization of activated microglia with NT-3 in the ipsilateral side in comparison to the contralateral side and control animals is shown in Figure 10 (yellow arrowheads). Note the close spatial appositions between NT-3-containing neurons (asterisks in Figure 10) and microglial cells (white arrows in Figure 10). Regarding astrocytes, as GFAP immunostaining in the ipsilateral side was similar at all the time points studied after the lesion in comparison to the contralateral side and control animals, a representative example of the colocalization of GFAP and NT-3 in the ipsilateral AVCN at 7d post-lesion (yellow arrows) is shown in Figure 11.

\section{DISCUSSION}

The present study demonstrates that UCHL, which causes a progressive decline in cochlear nerve activity, leads initially to an increase in microglial but not astroglial activation in the AVCN of adult rats, at least up to $15 \mathrm{~d}$ after the lesion. At 1 and $4 \mathrm{~d}$ following unilateral ossicle removal, Ibal immunostained cells were larger and darker in the ipsilateral AVCN when compared with those in the contralateral side and control animals. These observations were confirmed by significant increases in the mean cross-sectional areas of microglial cells and increases in the mean gray levels of Ibal immunostaining. When the expression and distribution of NT-3 and its colocalization with microglial and astroglial markers was investigated, we observed that NT-3 levels peaked by day 4 post-lesion, and that most labeling was concentrated in neuronal cell bodies and axons. Only few, scattered glial cells expressed this neurotrophin in control animals and following monoaural hearing loss. These findings suggest that microglial cells contribute to restore impaired synaptic function following UCHL.

Interrupted conduction of sound waves to the inner ear by means of unilateral middle ear ossicle removal has been reported to modify the activity of auditory neurons (Woolf et al., 1983; Tucci et al., 1999, 2001, 2002). In this regard, UCHL in gerbils results in either increases or decreases in 2-deoxyglucose (2-DG) uptake in the ipsilateral cochlear nucleus depending on whether the animals are maintained in silence following the 2-DG injection (Woolf et al., 1983) or exposed to sound (Tucci et al., 2001). Also, cytochrome oxidase activity has been shown to decrease in the ipsilateral cochlear nucleus and to increase on the contralateral side of experimental animals (Tucci et al., 2002). In agreement with these studies, our results also demonstrate decreased activity in the ipsilateral cochlear nucleus after UCHL. In this regard, increases in auditory thresholds and decrease in waves amplitudes in the ipsilateral side to the lesion were indicative of reduced levels of cochlear inputs to auditory nuclei leading to the suggestion that auditory circuitry is altered following unilateral hearing loss. Supporting this idea, increases in the number of cochlear nucleus neurons projecting ipsilaterally to the inferior colliculus of the unmanipulated side (Nordeen et al., 1983; Moore and Kitzes, 1985; Moore and Kowalchuk, 1988; Moore, 1994) and increased calcium influx in deafferented auditory brainstem nuclei that project to the inferior colliculus contralateral to the lesion (Fuentes-Santamaria et al., 2003, 2005; Alvarado et al., 2004) have been observed after experimental hearing loss in gerbils and ferrets.

The magnitude of the effects of UCHL on synaptic transmission varies depending on the species, the age of the animal when hearing loss occurs and the lesion paradigm. In the cochlear nucleus of adult guinea pigs, long-term plastic changes in GABA, glycine and aspartate uptake and release take place after middle ear ossicle removal (Potashner et al., 1997; Suneja et al., 1998). Previous studies have demonstrated that short and long-term alterations in receptor trafficking at synapses also occur in the cochlear nucleus of adult rats following monoaural earplugging (Whiting et al., 2009; Wang et al., 2011). Particularly by $1 \mathrm{~d}$ after unilateral hearing loss, GluA3 subunits of the AMPA receptor are upregulated at auditory synapses on cochlear nucleus projection neurons while glycine receptor $\alpha 1$ subunits are downregulated at inhibitory synapses suggesting that decreased auditory nerve activity compromises synaptic function.

Over the years, a number of studies have demonstrated that glial cells play a pivotal role as regulators of synaptic stability in response to brain damage (Bruce-Keller, 1999; Hanisch and Kettenmann, 2007). Particularly in the cochlear nucleus, bilateral cochlear ablation triggers a microglial activation process as early as $16 \mathrm{~h}$ post-lesion. This response peaks at $24 \mathrm{~h}$ when the intracellular levels of Ibal are increased and microglial cells have adopted a phenotype characterized by irregularly shaped hypertrophic cell bodies with very few short processes (Fuentes-Santamaria et al., 2012). The present findings indicate that reduced sound 


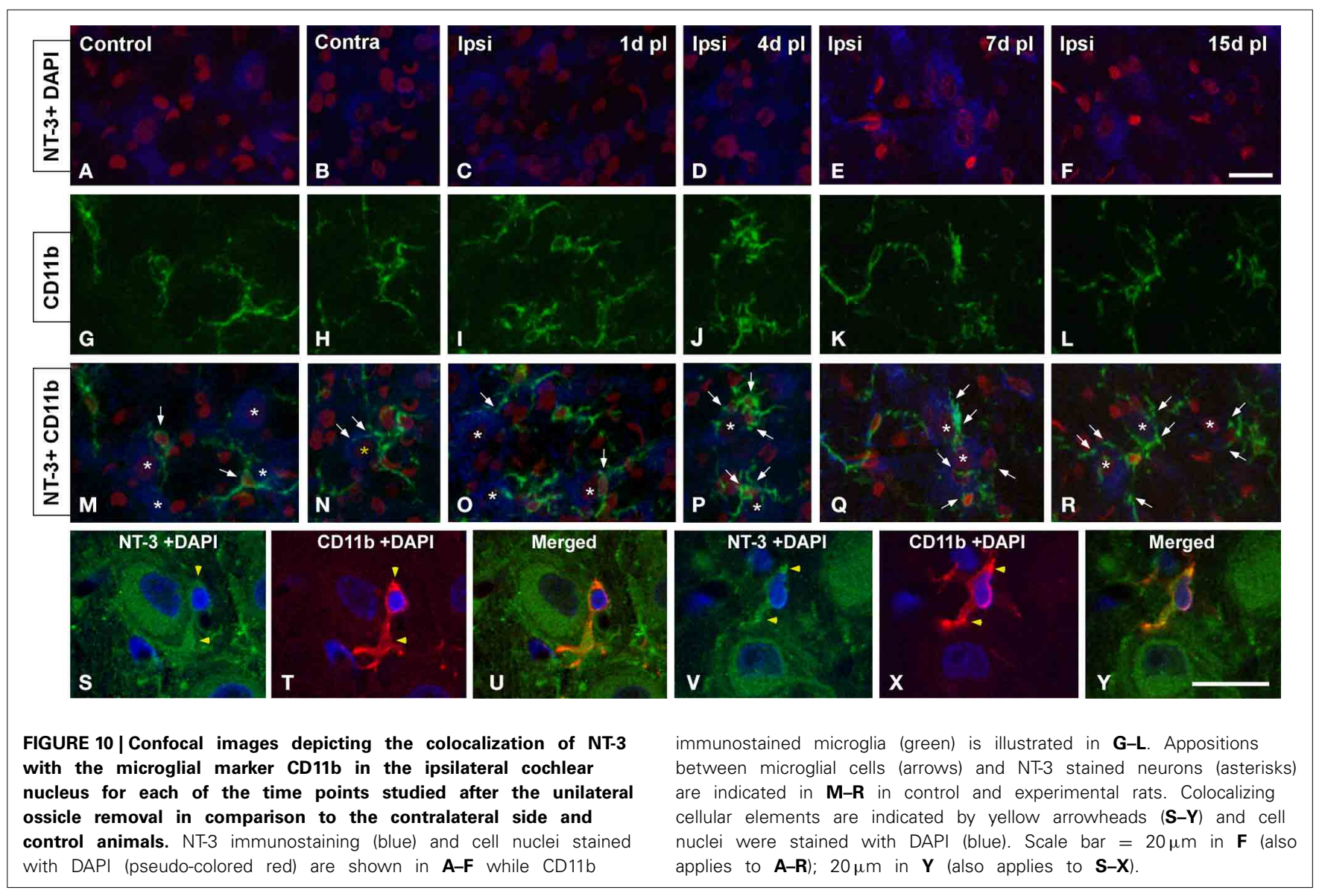

transmission to the cochlea also triggers a microglial reaction in the cochlear nucleus that is already present by 1d following the lesion and reaches maximal levels by $4 \mathrm{~d}$ post-lesion, a time point at which activated microglia is seen in apposition to activitydeprived auditory neurons. This functional relationship has also been corroborated by electron microscopic observations demonstrating that activated microglial processes are localized in the neuropil contacting nearby cellular elements following the lesion. These ultrastructural observations are in agreement with previous studies suggesting that microglia-neuronal interactions are critical to regulate synaptic activity (Skibo et al., 2000; Shapiro et al., 2009).

One of the mechanisms used by glial cells to facilitate the exchange of cellular signals and restore synaptic homeostasis is to increase the production and release of growth factors and cytokines (Cullheim and Thams, 2007). In this regard, upregulation of IGF- 1 and IL- $1 \beta$ levels in cochlear nucleus neurons but not in glial cells has been observed in adult rats at 1,7 , and $15 \mathrm{~d}$ post-ablation suggesting that deprived auditory nucleus neurons do not require additional IGF- 1 and IL- $1 \beta$ synthesis by glial cells to re-establish affected synaptic circuits (Fuentes-Santamaria et al., 2007, 2013). Neurotrophins are also signaling molecules expressed by neurons and microglia that serve trophic roles in the normal brain (Elkabes et al., 1996; Zhang et al., 2007). In agreement with our findings, NT-3 immunostaining in rats and gerbils is localized within the cell body cytoplasm as well as in the proximal dendrites and axon hillock of cochlear nucleus neurons in the adult and developing brain (Burette et al., 1998; Hafidi, 1999; Tierney et al., 2001; Hossain et al., 2002). Interestingly, recent findings in mice have provided evidence that NT-3 might also be expressed in primary cochlear afferents which are intermingled with the principal cells of the cochlear nucleus (Feng et al., 2010, 2012). Feng et al. (2010), observed that NT-3 staining was almost absent in the cytoplasm of cochlear nucleus neurons, and hence, they hypothesized that NT-3 might be released by supporting cells and inner hair cells in the inner ear, taken by spiral ganglion neuron peripheral processes and transported anterogradely to their endings in the cochlear nucleus. It is possible that the dissimilar findings between the study of Feng et al. (2010) and the aforementioned studies in rats and gerbils together with our observations might be due to species differences or to the antibodies used by the different authors that might be recognizing different epitopes. Although in the current study we have not evaluated whether NT-3 is also expressed in synaptic endings from spiral ganglion neurons, we cannot rule out the possibility that the punctate staining observed in the neuropil and surrounding cochlear nucleus neurons is presynaptic in nature.

Neurotrophic factors are activity-dependent molecular signals that play an important role in promoting auditory nerve fiber growth and spiral ganglion neuron survival and in restoring synaptic function and structure in response to hearing loss (Suneja et al., 2005; Fukui et al., 2012). Increased neurotrophin 

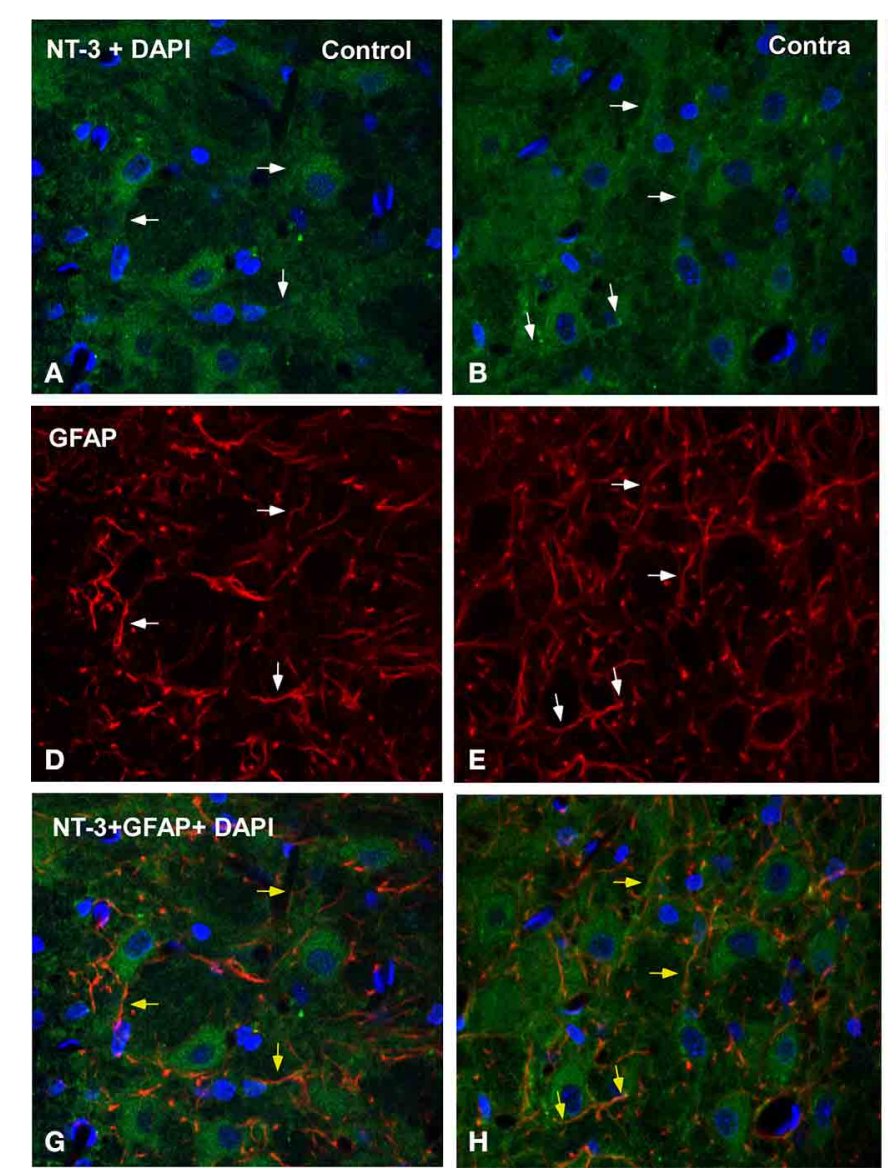
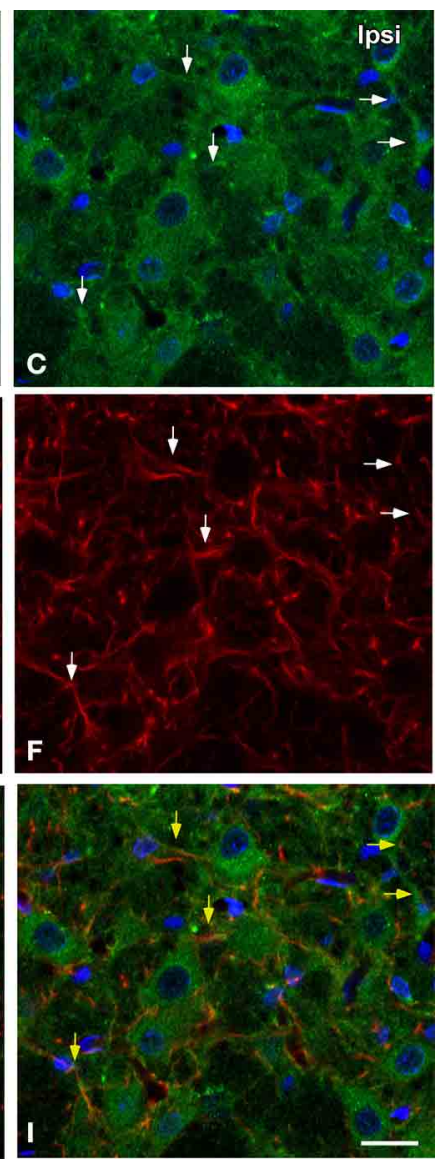

FIGURE 11 | Confocal images depicting the colocalization of NT-3 with the macroglial marker GFAP in the ipsilateral cochlear nucleus at 7d post-lesion in comparison to the contralateral side and control animals. NT-3 immunostaining (green) and cell nuclei stained with DAPI (blue) are represented in A-C, while astroglial staining (red) is shown in $\mathbf{D}-\mathbf{F}$. Colocalization of astrocytic processes with NT-3 is shown in G-I (yellow arrows). Colocalyzing cellular elements in $\mathbf{A}-\mathbf{F}$ are indicated by white arrows. Scale bar $=20 \mu \mathrm{m}$ in $\mathbf{I}$ (also applies to $\mathbf{A}-\mathbf{H}$ ). levels have been found in the adult cochlear nucleus of guinea pigs at $7 \mathrm{~d}$ after unilateral cochlear ablation and have been shown to contribute to synaptogenesis following cochlear damage (Suneja et al., 2005). Our results show that upregulation of neurotrophin levels within neurons occurs at $4 \mathrm{~d}$ following UCHL, a time point at which the microglial response reached maximal levels. This upregulation, together with the fact that microglial cells did not increase NT-3 levels at any of the time points studied following the lesion, indicates that transient increases in NT-3 likely contributing to preservation of synaptic function in the cochlear nucleus after UCHL, are part of activity-modulated neurotrophic mechanisms involving cochlear neurons, but not microglial cells.

In this study we did not find evidence of astrocytes activation at any of the time points included in this study. This suggests that these glial cells may not contribute directly to neuronal and synaptic adaptations to diminished activity in the cochlear nucleus after conductive hearing loss. The ultrastructural features of astrocytes described in this study are in agreement with those presented under normal conditions in different brain structures (Aoiki, 1992; Novikov et al., 2000). Astroglial reaction has been described in the cochlear nucleus after uni- or bilateral cochleotomy (Lurie and Rubel, 1994; De Waele et al., 1996; Campos Torres et al., 1999; Insausti et al., 1999; Lurie and Durham, 2000; Fredrich et al., 2013). In the adult rat, it reaches maximal levels by $7 \mathrm{~d}$ post-ablation when degeneration and reactive synaptogenesis are in full progress. The fact that astrogliosis seems to be more protracted and less persistent than microglial activation has led to the hypothesis that differences in the temporal pattern of activation of both cell types may reflect cooperative interactions to facilitate adult synaptogenesis following deafness (Fuentes-Santamaria et al., 2013). The fact that we do not see an astroglial reactive component, at least up to day 15 post-lesion, may complement this hypothesis by providing evidence that perhaps neuronal degeneration, like after cochleotomy, is required to unleash an astroglial reaction, whereas microglial cells react to adapt neurons and circuits to a broader range of lesion situations, ranging from attenuated activity to full-scale neuronal degeneration. Finally, although previous studies have shown that astrocytes might express NT-3 (Burette et al., 1998; Feng et al., 2012), our observations indicate that only a small subpopulation expresses this neurotrophin, both in control and experimental animals. In summary, our results provide evidence that microglial 
cells, but not astrocytes, are involved in a transient response to diminished activity in the cochlear nucleus, likely aimed at preserving or adapting synaptic function. Although further studies are still required, these findings suggest that modulation of the microglial responses could be a pharmacological target of interest for the treatment of pathologies that induce hearing loss.

\section{AUTHOR CONTRIBUTORS}

All authors had full access to all the data in the study and take responsibility for the integrity of the data and the accuracy of the data analysis. Study concept and design: Verónica FuentesSantamaría, Juan C. Alvarado. Acquisition of data: Verónica Fuentes-Santamaría, Juan C. Alvarado, Diego F. López-Muñoz, Pedro Melgar-Rojas and María C. Gabaldón-Ull. Statistical analysis and interpretation of data: Verónica Fuentes-Santamaría and Juan C. Alvarado. Drafting of the manuscript: Verónica Fuentes-Santamaría and Juan C. Alvarado. Critical revision of the manuscript for important intellectual content: Verónica FuentesSantamaría, Juan C. Alvarado, and José M. Juiz. Obtaining funding: Verónica Fuentes-Santamaría, Juan C. Alvarado, and José M. Juiz.

\section{ACKNOWLEDGMENTS}

This study was supported by Programa I3 del Ministerio de Ciencia e Innovaciün (I320101590 to Verónica FuentesSantamaría and I320101589 to Juan C. Alvarado) and Ministerio de Ciencia e Innovación (BFU2012-39982-C02-02 to José M. Juiz).

\section{REFERENCES}

Alvarado, J. C., Fuentes-Santamaria, V., Franklin, S. R., Brunso-Bechtold, J. K., and Henkel, C. K. (2007). Synaptophysin and insulin-like growth factor-1 immunostaining in the central nucleus of the inferior colliculus in adult ferrets following unilateral cochlear removal: a densitometric analysis. Synapse 61, 288-302. doi: 10.1002/syn.20373

Alvarado, J. C., Fuentes-Santamaria, V., Franklin, S. R., Brunso-Bechtold, J. K., and Henkel, C. K. (2005). Unilateral cochlear ablation in adult ferrets results in upregulation in calretinin immunostaining in the central nucleus of the inferior colliculus. Neuroscience 136, 957-969. doi: 10.1016/j.neuroscience.2005.04.022

Alvarado, J. C., Fuentes-Santamaría, V., Gabaldón-Ull, M. C., Blanco, J. L., and Juiz, J. M. (2014). Wistar rats: a forgotten model of age-related hearing loss. Front. Aging Neurosci. 5:29. doi: 10.3389/fnagi.2014.00029

Alvarado, J. C., Fuentes-Santamaria, V., Henkel, C. K., and Brunso-Bechtold, J. K. (2004). Alterations in calretinin immunostaining in the ferret superior olivary complex after cochlear ablation. J. Comp. Neurol. 470, 63-79. doi: 10.1002/cne. 11038

Alvarado, J. C., Fuentes-Santamaría,V., Jareño-Flores, T., Blanco, J. L., and Juiz, J. M. (2012). Normal variations in the morphology of auditory brainstem response (ABR) waveforms: a study in Wistar rats. Neurosci. Res. 73, 302-311. doi: 10.1016/j.neures.2012.05.001

Aoiki, C. (1992). B-Adrenergic receptors: astrocytic localization in the adult visual cortex and their relation to catecholamine axon terminals as revealed by electron microscopic immunocytochemistry. J. Neurosci. 12, 781-792.

Benson, C. G., Gross, J. S., Suneja, S. J., and Potashner, S. J. (1997). Synaptophysin immunoreactivity in the cochlear nucleus after unilateral cochlear or ossicular removal. Synapse 25, 243-257.

Bruce-Keller, A. J. (1999). Microglial-neuronal interactions in synaptic damage and recovery. J. Neurosci. Res. 58, 191-201.

Burette, A., Belliot, G., Albuisson, E., and Romand, R. (1998). Localization of neurotrophin-3-like immunoreactivity in the rat cochlear nucleus. Microsc. Res. Tech. 41, 224-233.

Caicedo, A., d'Aldin, C., Eybalin, M., and Puel, J. L. (1997). Temporary sensory deprivation changes calcium-binding proteins levels in the auditory brainstem. J. Comp. Neurol. 378, 1-15.
Campos-Torres, A., Touret, M., Vidal, P. P., Barnum, S., and De Waele, C. (2005). The differential response of astrocytes within the vestibular and cochlear nuclei following unilateral labyrinthectomy or vestibular afferent activity blockade by transtympanic tetrodotoxin injection in the rat. Neuroscience 130, 853-865. doi: 10.1016/j.neuroscience.2004.08.052

Campos Torres, A., Vidal, P. P., and De Waele, C. (1999). Evidence for a microglial reaction within the vestibular and cochlear nuclei following inner ear lesion in the rat. Neuroscience 92, 1475-1490. doi: 10.1016/S0306-4522(99) 00078-0

Cant, N. B., and Benson, C. G. (2003). Parallel auditory pathways: projection patterns of the different neuronal populations in the dorsal and ventral cochlear nuclei. Brain Res. Bull. 60, 457-474. doi: 10.1016/S0361-9230(03)00050-9

Cediel, R., Riquelme, R., Contreras, J., Díaz, A., and Varela-Nieto, I. (2006). Sensorineural hearing loss in insulin-like growth factor I-null mice: a new model of human deafness. Eur. J. Neurosci. 23, 587-590. doi: 10.1111/j.14609568.2005.04584.x

Conlee, J. W., and Parks, T. N. (1981). Age- and position-dependent effects of monaural acoustic deprivation in nucleus magnocellularis of the chicken. J. Comp. Neurol. 202, 373-384. doi: 10.1002/cne.902020307

Cullheim, S., and Thams, S. (2007). The microglial networks of the brain and their role in neuronal network plasticity after lesion. Brain Res. Rev. 55, 89-96. doi: 10.1016/j.brainresrev.2007.03.012

De Waele, C., Campos-Torres, A., Josset, P., and Vidal, P. P. (1996). Evidence for reactive astrocytes in rat vestibular and cochlear nuclei following unilateral inner ear lesion. Eur. J. Neurosci. 8, 2006-2018. doi: 10.1111/j.14609568.1996.tb01344.x

Elkabes, S., DiCicco-Bloom, E. M., and Black, I. B. (1996). Brain microglia/macrophages express neurotrophins that selectively regulate microglial proliferation and function. J. Neurosci. 16, 2508-2521.

Feng, J., Bendiske, J., and Morest, D. K. (2010). Postnatal development of NT3 and TrkC in mouse ventral cochlear nucleus. J. Neurosci. Res. 88, 86-94. doi: 10.1002/jnr.22179

Feng, J., Bendiske, J., and Morest, D. K. (2012). Degeneration in the ventral cochlear nucleus after severe noise damage in mice. J. Neurosci. Res. 90, 831-841. doi: 10.1002/jnr.22793

Ferguson, M. O., Cook, R. D., Hall, J. W. 3rd., Grose, J. H., and Pillsbury, H. C. 3rd. (1998). Chronic conductive hearing loss in adults: effects on the auditory brainstem response and masking-level difference. Arch. Otolaryngol. Head Neck Surg. 124, 678-685. doi: 10.1001/archotol.124.6.678

Fredrich, M., Zeber, A. C., Hildebrandt, H., and Illing, R. B. (2013). Differential molecular profiles of astrocytes in degeneration and re-innervation after sensory deafferentation of the adult rat cochlear nucleus. Eur. J. Neurosci. 38, 2041-2056. doi: $10.1111 /$ ejn. 12200

Fria, T. J., and Sabo, D. L. (1980). Auditory brainstem responses in children with otitis media with effusion. Ann. Otol. Rhinol. Laryngol. Suppl. 89(3 Pt 2), 200-206.

Fuentes-Santamaria, V., Alvarado, J. C., Brunso-Bechtold, J. K., and Henkel, C. K. (2003). Upregulation of calretinin immunostaining in the ferret inferior colliculus after cochlear ablation. J. Comp. Neurol. 460, 585-596. doi: 10.1002/cne.10676

Fuentes-Santamaría, V., Alvarado, J. C., Gabaldón-Ull, M. C., and Juiz, J. M. (2013). Upregulation of insulin-like growth factor and interleukin $1 \beta$ occurs in neurons but not in glial cells in the cochlear nucleus following cochlear ablation. J. Comp. Neurol. 521, 3478-3499. doi: 10.1002/cne.23362

Fuentes-Santamaria, V., Alvarado, J. C., Henkel, C. K., and Brunso-Bechtold, J. K. (2007). Cochlear ablation in adult ferrets results in changes in insulinlike growth factor-1 and synaptophysin immunostaining in the cochlear nucleus. Neuroscience 148, 1033-1047. doi: 10.1016/j.neuroscience.2007. 07.026

Fuentes-Santamaria, V., Alvarado, J. C., and Juiz, J. M. (2012). Long-term interaction between microglial cells and cochlear nucleus neurons after bilateral cochlear ablation. J. Comp. Neurol. 520, 2974-2990. doi: 10.1002/cne. 23088

Fuentes-Santamaria, V., Alvarado, J. C., Taylor, A. R., Brunso-Bechtold, J. K., and Henkel, C. K. (2005). Quantitative changes in calretinin immunostaining in the cochlear nuclei after unilateral cochlear removal in young ferrets. J. Comp. Neurol. 483, 458-475. doi: 10.1002/cne.20437

Fukui, H., Wong, H. T., Beyer, L. A., Case, B. G., Swiderski, D. L., Di Polo, A., et al. (2012). BDNF gene therapy induces auditory nerve survival and fiber sprouting in deaf Pou4f3 mutant mice. Sci. Rep. 2, 838. doi: 10.1038/srep00838 
Garcia-Pino, E., Caminos, E., and Juiz, J. M. (2010). KCNQ5 reaches synaptic endings in the auditory brainstem at hearing onset and targeting maintenance is activity-dependent. J. Comp. Neurol. 518, 1301-1314. doi: 10.1002/cne. 22276

Guthrie, K. M., Nguyen, T., and Gall, C. M. (1995). Insulin-like growth factor-1 mRNA is increased in deafferented hippocampus: spatiotemporal correspondence of a trophic event with axon sprouting. J. Comp. Neurol. 352, 147-160. doi: $10.1002 /$ cne.903520111

Hafidi, A. (1999). Distribution of BDNF, NT-3 and NT-4 in the developing auditory brainstem. Int. J. Dev. Neurosci. 17, 285-294. doi: 10.1016/S07365748(99)00043-X

Hanisch, U. K. (2002). Microglia as a source and target of cytokines. Glia 40, 140-155. doi: 10.1002/glia.10161

Hanisch, U. K., and Kettenmann, H. (2007). Microglia: active sensor and versatile effector cells in the normal and pathologic brain. Nat. Neurosci. 10, 1387-1394. doi: 10.1038/nn 1997

Hossain, W. A., Brumwell, C. L., and Morest, D. K. (2002). Sequential interactions of fibroblast growth factor-2, brain derived neurotrophic factor, neurotrophin3 , and their receptors define critical periods in the development of cochlear ganglion cells. Exp. Neurol. 175, 138-151. doi: 10.1006/exnr.2002.7872

Huang, X., Chen, S., and Tietz, E. (1996). Immunocytochemical detection of regional protein changes in rat brain sections using computer-assisted image analysis. J. Histochem. Cytochem. 44, 981-987. doi: 10.1177/44.9. 8773563

Hutson, K. A., Durham, D., and Tucci, D. L. (2007). Consequences of unilateral hearing loss: time dependent regulation of protein synthesis in auditory brainstem nuclei. Hear. Res. 233, 124-134. doi: 10.1016/j.heares.2007. 08.003

Hwang, I. K., Yoo, K. Y., Park, S. K., An, S. J., Lee, J. Y., Choi, S. Y., et al. (2004). Expression and changes of endogenous insulin-like growth factor-1 in neurons and glia in the gerbil hippocampus and dentate gyrus after ischemic insult. Neurochem. Int. 45, 149-156. doi: 10.1016/j.neuint.2003.10.006

Insausti, A. M., Cruz-Orive, L. M., Jáuregui, I., Manrique, M., and Insausti, R. (1999). Stereological assessment of the glial reaction to chronic deafferentation of the cochlear nuclei in the macaque monkey (Macaca fascicularis). J. Comp. Neurol. 414, 485-494.

Lurie, D. I., and Durham, D. (2000). Neuronal death, not axonal degeneration, results in significant gliosis within the cochlear nucleus of adult chickens. Hear. Res. 149, 178-188. doi: 10.1016/S0378-5955(00)00181-7

Lurie, D. I., and Rubel, E. W. (1994). Astrocyte proliferation in the chick auditory brainstem following cochlea removal. J. Comp. Neurol. 46, 276-288. doi: 10.1002/cne.903460207

Madathil, S. K., Evans, H. N., and Saatman, K. E. (2010). Temporal and regional changes in IGF-1/IGF-1R signaling in the mouse brain after traumatic brain injury. J. Neurotrauma 27, 95-107. doi: 10.1089/neu.2009.1002

Moore, D. R. (1994). Auditory brainstem of the ferret: long survival following cochlear removal progressively changes projections from the cochlear nucleus to the inferior colliculus. J. Comp. Neurol. 339, 301-310. doi: $10.1002 /$ cne. 903390209

Moore, D. R., Hutchings, M. E., King, A. J., and Kowalchuk, N. E. (1989). Auditory brainstem of the ferret: some effects of rearing with a unilateral earplug on the cochlea, cochlear nucleus, and projections to the inferior colliculus. J. Neurosci. 9, 1213-1222.

Moore, D. R., and Kitzes, L. M. (1985). Projections from the cochlear nucleus to the inferior colliculus in normal and neonatally cochlea-ablated gerbils. J. Comp. Neurol. 240, 180-195. doi: 10.1002/cne.902400208

Moore, D. R., and Kowalchuk, N. E. (1988). An anomaly in the auditory brain stem projections of hypopigmented ferrets. Hear. Res. 35, 275-278. doi: 10.1016/0378-5955(88)90125-6

Nordeen, K. W., Killackey, H. P., and Kitzes, L. M. (1983). Ascending projections to the inferior colliculus following unilateral cochlear ablation in the neonatal gerbil, Meriones unguiculatus. J. Comp. Neurol. 214, 144-153. doi: $10.1002 /$ cne. 902140204

Novikov, L. N., Novikova, L. N., Holmberg, P., and Kellerth, J. (2000). Exogenous brain-derived neurotrophic factor regulates the synaptic composition of axonally lesioned and normal adult rat motoneurons. Neuroscience 100, 171-181. doi: 10.1016/S0306-4522(00)00256-6

Parish, C. L., Finkelstein, D. I., Tripanichkul, W., Satoskar, A. R., Drago, J., and Horne, M. K. (2002). The role of interleukin-1, interleukin-6, and glia in inducing growth of neuronal terminal arbors in mice. J. Neurosci. 22, 8034-8041. Available online at: http://www.jneurosci.org/content/22/18/8034 full

Potashner, S. J., Suneja, S. K., and Benson, C. G. (1997). Regulation of D-aspartate release and uptake in adult brain stem auditory nuclei after unilateral middle ear ossicle removal and cochlear ablation. Exp. Neurol. 148, 222-235. doi: 10.1006/exnr.1997.6641

Rothwell, N. J., and Luheshi, G. N. (2000). Interleukin 1 in the brain: biology, pathology and therapeutic target. Trends Neurosci. 23, 618-625. doi: 10.1016/S0166-2236(00)01661-1

Shapiro, L. A., Perez, Z. D., Foresti, M. L., Arisi, G. M., and Ribak, C. E. (2009). Morphological and ultrastructural features of Ibal-immunolabeled microglial cells in the hippocampal dentate gyrus. Brain Res. 1266, 29-36. doi: 10.1016/j.brainres.2009.02.031

Skibo, G. G., Nikonenko, I. R., Savchenko, V. L., and McKanna, J. A. (2000). Microglia in organotypic hippocampal slice culture and effects of hypoxia: ultrastructure and lipocortin-1 immunoreactivity. Neuroscience 96, 427-438. doi: 10.1016/S0306-4522(99)00562-X

Suneja, S. K., Potashner, S. J., and Benson, C. G. (1998). Plastic changes in glycine and GABA release and uptake in adult brain stem auditory nuclei after unilateral middle ear ossicle removal and cochlear ablation. Exp. Neurol. 151, 273-288. doi: 10.1006/exnr.1998.6812

Suneja, S. K., Yan, L., and Potashner, S. J. (2005). Regulation of NT-3 and BDNF levels in guinea pig auditory brain stem nuclei after unilateral cochlear ablation. J. Neurosci. Res. 80, 381-390. doi: 10.1002/jnr.20457

Tierney, T. S. P., Doubell, T., Xia, G., and Moore, D. R. (2001). Development of brain-derived neurotrophic factor and neurotrophin-3 immunoreactivity in the lower auditory brainstem of the postnatal gerbil. Eur. J. Neurosci. 14, 785-793. doi: 10.1046/j.0953-816x.2001.01690.x

Touzani, O., Boutin, H., Chuquet, J., and Rothwell, N. (1999). Potential mechanisms of interleukin-1 involvement in cerebral ischaemia. J. Neuroimmunol. 100, 203-215. doi: 10.1016/S0165-5728(99)00202-7

Tucci, D., Cant, N. B., and Durham, D. (2002). Conductive hearing loss results in changes in cytochrome oxidase activity in gerbil central auditory system. J. Assoc. Res. Otolaryngol. 3, 89-106. doi: 10.1007/s101620010091

Tucci, D. L., Cant, N. B., and Durham, D. (1999). Conductive hearing loss results in a decrease in central auditory system activity in the young gerbil. Laryngoscope 109, 1359-1371. doi: 10.1097/00005537-199909000-00001

Tucci, D. L., Cant, N. B., and Durham, D. (2001). Effects of conductive hearing loss on gerbil central auditory system activity in silence. Hear. Res. 155, 124-132. doi: 10.1016/S0378-5955(01)00256-8

Tucci, D. L., and Rubel, E. W. (1985). Afferent influences on brain stem auditory nuclei of the chicken: effects of conductive and sensorineural hearing loss on $\mathrm{n}$. magnocellularis. J. Comp. Neurol. 238, 371-381. doi: 10.1002/cne.902380402

Wang, H., Yin, G., Rogers, K., Miralles, C., De Blas, A. L., and Rubio, M. E (2011). Monaural conductive hearing loss alters the expression of the GluA3 AMPA and glycine receptor $\alpha 1$ subunits in bushy and fusiform cells of the cochlear nucleus. Neuroscience 199, 438-451. doi: 10.1016/j.neuroscience.2011. 10.021

Watt, J. A., and Hobbs, N. K. (2000). Interleukin-1beta immunoreactivity in identified neurons of the rat magnocellular neurosecretory system: evidence for activity-dependent release. J. Neurosci. Res. 60, 478-489. doi: 10.1002/(SICI) 1097-4547(20000515)60:4<478::AID-JNR6>3.0.CO;2-R

Whiting, B., Moiseff, A., and Rubio, M. E. (2009). Cochlear nucleus neurons redistribute synaptic AMPA and glycine receptors in response to monaural conductive hearing loss. Neuroscience 163, 1264-1276. doi: 10.1016/j.neuroscience.2009.07.049

Winsky, L., and Jacobowitz, D. M. (1995). Effects of unilateral cochlea ablation on the distribution of calretinin mRNA and immunostaining in the guinea pig ventral cochlear nucleus. J. Comp. Neurol. 354, 564-582. doi: $10.1002 / \mathrm{cne} .903540407$

Wise, A. K., Tu, T., Atkinson, P. J., Flynn, B. O., Sgro, B. E., Hume, C., et al. (2011). The effect of deafness duration on neurotrophin gene therapy for spiral ganglion neuron protection. Hear. Res. 278, 69-76. doi: 10.1016/j.heares.2011. 04.010

Woolf, N. K., Sharp, F. R., Davidson, T. M., and Ryan, A. F. (1983). Cochlear and middle ear effects on metabolism in the central auditory pathway during silence: a 2-deoxyglucose study. Brain Res. 274, 119-127. doi: 10.1016/00068993(83)90526-7 
Yao, W., and Godfrey, D. A. (1997). Densitometric evaluation of markers for cholinergic transmission in rat superior olivary complex. Neurosci. Lett. 229, 21-24. doi: 10.1016/S0304-3940(97)00400-X

Zhang, H. T., Li, L. Y., Zou, X. L., Song, X. B., Hu, Y. L., Feng, Z. T., et al. (2007). Immunohistochemical distribution of NGF, BDNF, NT-3, and NT4 in adult rhesus monkey brains. J. Histochem. Cytochem. 55, 1-19. doi: 10.1369/jhc.6A6952.2006

Conflict of Interest Statement: The Associate Editor, Monica Muñoz-Lopez, and the Review Editor, Alino Martinez-Marcos, declare that, despite being affiliated to the same institution as the authors, the review process was handled objectively and no conflict of interest exists. The authors declare that the research was conducted in the absence of any commercial or financial relationships that could be construed as a potential conflict of interest.
Received: 21 July 2014; accepted: 19 September 2014; published online: 13 October 2014.

Citation: Fuentes-Santamaría V, Alvarado JC, López-Muñoz DF, Melgar-Rojas P, Gabaldón-Ull MC and Juiz JM (2014) Glia-related mechanisms in the anteroventral cochlear nucleus of the adult rat in response to unilateral conductive hearing loss. Front. Neurosci. 8:319. doi: 10.3389/fnins.2014.00319

This article was submitted to Auditory Cognitive Neuroscience, a section of the journal Frontiers in Neuroscience.

Copyright (C) 2014 Fuentes-Santamaría, Alvarado, López-Muñoz, Melgar-Rojas, Gabaldon-Ull and Juiz. This is an open-access article distributed under the terms of the Creative Commons Attribution License (CC BY). The use, distribution or reproduction in other forums is permitted, provided the original author(s) or licensor are credited and that the original publication in this journal is cited, in accordance with accepted academic practice. No use, distribution or reproduction is permitted which does not comply with these terms. 